\title{
The Scientific Foundations of Forecasting Magnetospheric Space Weather
}

\author{
J.P. Eastwood ${ }^{1}$ R. Nakamura ${ }^{2}$. L. Turc $^{3}$. \\ L. Mejnertsen ${ }^{1} \cdot$ M. Hesse ${ }^{4}$
}

Received: 29 March 2017 / Accepted: 7 July 2017

(C) The Author(s) 2017. This article is published with open access at Springerlink.com

\begin{abstract}
The magnetosphere is the lens through which solar space weather phenomena are focused and directed towards the Earth. In particular, the non-linear interaction of the solar wind with the Earth's magnetic field leads to the formation of highly inhomogenous electrical currents in the ionosphere which can ultimately result in damage to and problems with the operation of power distribution networks. Since electric power is the fundamental cornerstone of modern life, the interruption of power is the primary pathway by which space weather has impact on human activity and technology. Consequently, in the context of space weather, it is the ability to predict geomagnetic activity that is of key importance. This is usually stated in terms of geomagnetic storms, but we argue that in fact it is the substorm phenomenon which contains the crucial physics, and therefore prediction of substorm occurrence, severity and duration, either within the context of a longer-lasting geomagnetic storm, but potentially also as an isolated event, is of critical importance. Here we review the physics of the magnetosphere in the frame of space weather forecasting, focusing on recent results, current understanding, and an assessment of probable future developments.
\end{abstract}

Keywords Space weather · Magnetosphere - Geomagnetic storm · Substorm · Computer simulation

The Scientific Foundation of Space Weather

Edited by Rudolf von Steiger, Daniel Baker, André Balogh, Tamás Gombosi, Hannu Koskinen and Astrid Veronig

\footnotetext{
J.P. Eastwood

jonathan.eastwood@imperial.ac.uk

1 The Blackett Laboratory, Imperial College London, London, UK

2 Space Research Institute, Austrian Academy of Sciences, Graz, Austria

3 Department of Physics, University of Helsinki, Helsinki, Finland

4 Birkeland Centre for Space Science, Department of Physics and Technology, University of Bergen, Bergen, Norway
} 


\section{Magnetospheric Space Weather-Initial Considerations}

It is well known that space weather pertains to the conditions in all regions of space that can harm or disrupt human activity and technology both in space and on the ground (Hapgood 2011, 2012; Schrijver et al. 2015). Space weather is distinct from solar-terrestrial physics, and heliophysics more generally, because of its strong emphasis on societal impact (National Research Council 2008; Cannon et al. 2013). Since space weather is defined by its downstream effects, it is common practice to distinguish between three specific phenomena: radio blackouts, solar radiation storms and geomagnetic storms, which are monitored by various agencies at the national and international level.

In this article we aim to examine different aspects of the scientific foundations behind forecasting magnetospheric space weather. Although in some sense each of the three phenomena mentioned above can be considered 'magnetospheric' space weather (since they all generate impacts that occur inside the magnetosphere) only geomagnetic storms arise as a fundamental consequence of magnetospheric dynamics. Therefore here we will restrict the discussion to geomagnetic activity (of which storms are a manifestation), the underpinning science, and forecasting.

Before discussing the physics that controls magnetospheric activity, it is important to establish why geomagnetic storms are of interest for space weather as this immediately provides further focus and defines the processes that are relevant for magnetospheric space weather forecasting. It is well established that the primary channel by which space weather can generate a major socio-economic impact is through prolonged loss of power over an extended spatial area (Eastwood et al. 2017 and references therein). In the context of geomagnetic storms, the direct risk is from Ground Induced Currents (GICs). Ionospheric current systems, driven by magnetospheric activity, can cause rapidly varying magnetic field signatures at the Earth's surface; in turn these induce geo-electric fields, which then drive GICs that affect power grids in different ways: damage to physical infrastructure; the introduction of voltage instability which may trigger a blackout (without infrastructure damage); and interference with protection systems (Cannon et al. 2013). The most notable historical event with documented impact is the March 1989 geomagnetic storm, which is the largest of the space age but still less severe than the Carrington event, widely considered a reasonable worse-case scenario (Bolduc 2002; Erinmez et al. 2002; Cliver and Dietrich 2013).

Consequently, viewed through the lens of the socio-economic impact, forecasting magnetospheric space weather ultimately revolves around understanding the magnetospheric physics that controls the formation of GICs. Accurate forecasting of this, and magnetospheric space weather more generally depends on several factors. We will examine three in particular:

- The translation of L1 measurements to the nose of the magnetosphere-are the correct boundary conditions being applied to the magnetosphere?

- The physics that controls the behaviour of the magnetosphere-what is the current understanding of key processes based on recent spacecraft observations?

- Appropriateness of modelling approaches-in particular the use of global MHD simulations to capture dynamics and processes that are relevant for magnetospheric space weather forecasting.

In the final part of this review article we consider future developments, in light of present understanding and modelling capabilities. But first, we review fundamental aspects of the solar wind magnetosphere interaction, providing an overview of magnetospheric dynamics and discussing the relevance of substorms and storms for space weather. 


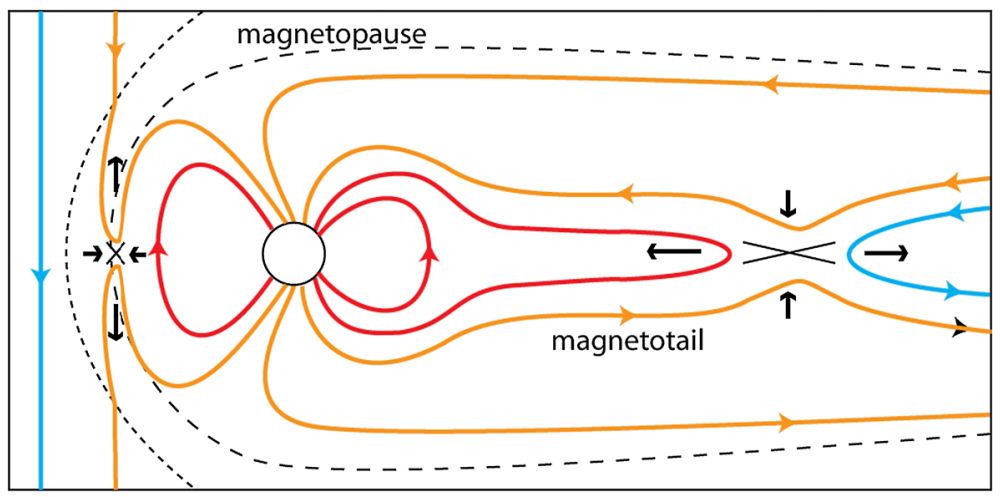

Fig. 1 A schematic of plasma circulation in the Earth's magnetosphere for southward IMF conditions. As originally proposed by Dungey, magnetic reconnection at the dayside magnetopause and in the magnetotail results in the concept of the open magnetosphere

\section{The Solar Wind Magnetosphere Interaction}

The dynamics of the Earth's magnetosphere are controlled by the solar wind Interplanetary Magnetic Field (IMF) (Dungey 1961). In particular, the stress applied by the solar wind on the Earth's magnetic field results in reconnection at the dayside magnetopause, creating open magnetic flux that is carried by the solar wind toward the night-side. The accumulated stress of the open magnetic field lines on the night-side leads to the formation of an elongated region called the magnetotail (see Fig. 1). Reconnection takes place between the oppositely directed magnetic fields at the center of the cross tail current sheet and the closed magnetic flux of the plasma sheet is transported back again toward the dayside completing the magnetospheric convection cycle. In this way, the global structures and long-time scale ( $>$ hours) properties of the Earth's magnetotail are controlled by magnetic flux transport as a consequence of the solar wind-magnetosphere interaction. The reconnection region in the magnetotail responsible for the magnetospheric convection is considered to be nominally located at a distance of about 100 to 200 Re downtail and is called the distant neutral line (e.g., Walker et al. 1999).

Whilst the original Dungey (1961) picture captures the essence of magnetospheric behavior, and is well known, there are two key features fundamental to real magnetospheric dynamics which it does not capture, and which are perhaps not as well known in the wider space weather user community: the Expanding/Contracting Polar Cap paradigm and the Near Earth Neutral Line model.

\subsection{The Expanding/Contracting Polar Cap Paradigm}

It should be emphasized that the rate of dayside and nightside reconnection are not in balance (Cowley and Lockwood 1992). This means that the amount of open flux in the magnetosphere (orange field lines in Fig. 1) varies with time (e.g., Milan 2015 and references therein). This in particular means that energy can be stored in the magnetic field of the magnetotail, and subsequently released by magnetotail reconnection. The ionospheric polar cap represents the region of magnetic field in the magnetosphere that is 'open', i.e. connected to the Earth at only one end. Dayside reconnection will increase the size of the polar cap, as it will reconnect solar wind plasma and magnetospheric field lines to form open field lines. 
Fig. 2 Example of how the size of the auroral oval changes in response to unbalanced dayside and nightside reconnection. The top two panels show the auroral oval at the start and end of a geomagnetic storm, as measured using the Sym-H index in panel (d). Panel (e) shows the rate of solar wind magnetosphere coupling. (Figure 2 from Milan 2009; Copyright 2009 by the American Geophysical Union, reproduced with permission.)

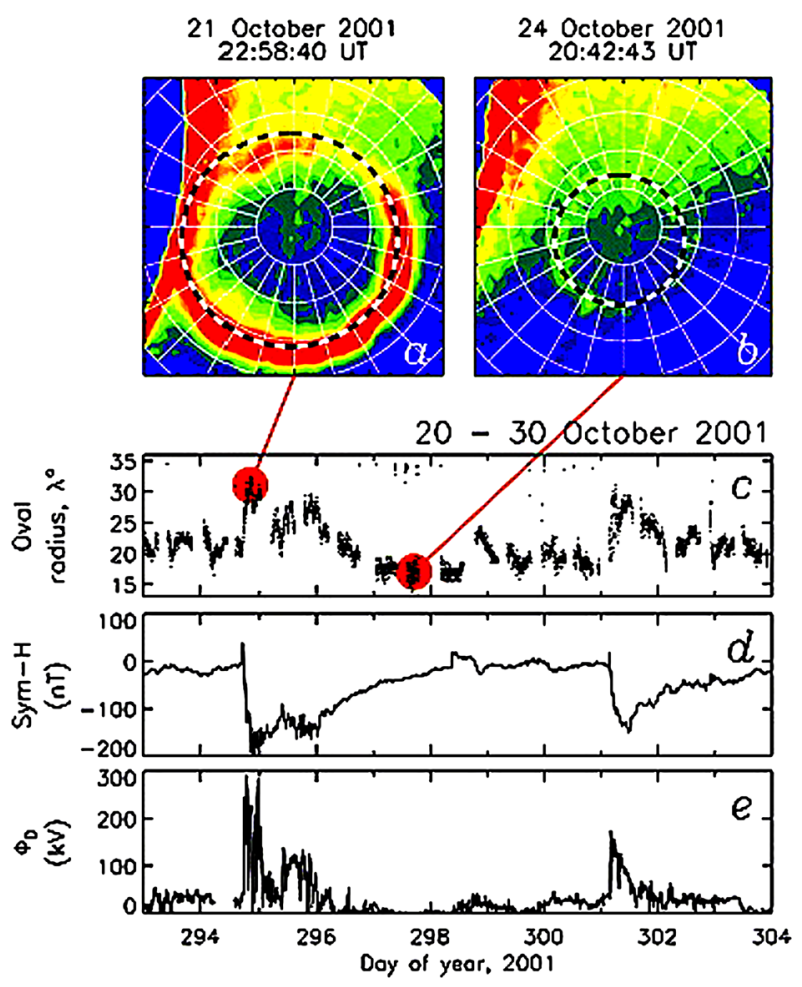

Nightside reconnection of open field lines in the northern and southern lobes will reduce the size of the polar cap (see Fig. 2) (Milan 2009). Consequently, if the rate of reconnection at the dayside and in the magnetotail do not match, the polar cap will change in size, and can expand or contract. Whilst the reality is more complex, with other modifying phenomena at work, a very basic prediction is that the polar cap should grow in size before a substorm onset, because energy is being deposited into the lobes by magnetopause reconnection, and it should reduce in size as a substorm occurs, because nightside reconnection is returning closed flux to the inner magnetosphere. This overall picture is known as the expanding/contracting polar cap paradigm. In summary, it may be interpreted as the extension of the open magnetosphere model to time dependent behaviour where the reconnection rates in the magnetotail and on the dayside do not match.

\subsection{Formation of the Near-Earth Neutral Line (NENL)}

It is now known that internal processes in the magnetotail lead to the formation of thin current sheets also in the closed tail field regions closer to Earth. Consequently reconnection may also take place closer to Earth (closer to $30 \mathrm{Re}$, down to about $\sim 12 \mathrm{Re}$ ) in a more explosive manner, resulting in the loss of the plasmasheet plasma tailward and drastic changes in the magnetotail configuration (Hones 1977; Baker et al. 1996). The overall dynamics of the magnetotail are quite well-defined in space and time, with the formation of a near-Earth neutral line leading to plasmoid release downtail (Slavin et al. 1984). This is illustrated in Fig. 3. A key feature of this process is that the inner edge of the magnetotail becomes more dipolar relative to the originally stretched tail current sheet. It is also important to note that 


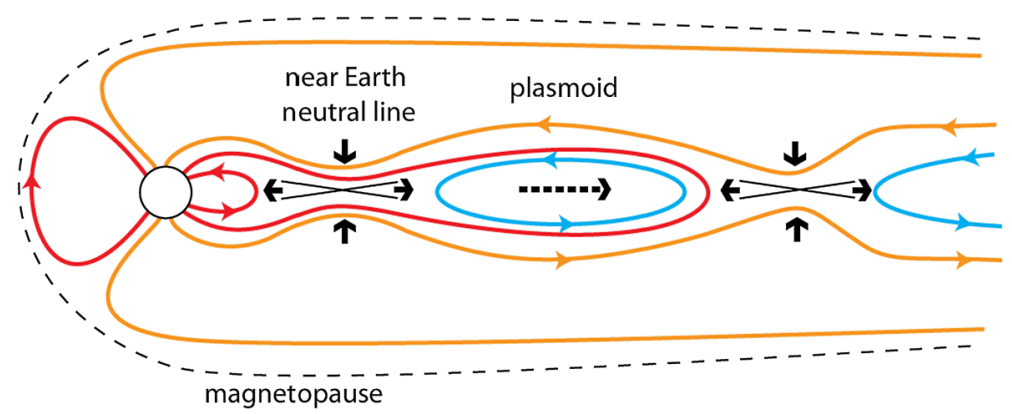

Fig. 3 Formation of the near Earth neutral line. This leads to the development of a plasmoid which is ejected downtail

this picture represents a cut through the magnetotail. Whilst the X-line and plasmoid does extend out of the page, it is limited in size (see, e.g., Eastwood and Kiehas 2015 and references therein). Consequently the dipolar region is approximately confined to the central region of the magnetotail, with consequences for magnetosphere-ionosphere coupling.

\subsection{Magnetospheric Substorms and Storms}

The elemental behaviour of the magnetosphere is the substorm (McPherron 1970; Rostoker et al. 1980), which has both a magnetospheric and auroral manifestation. The basic nature of substorms can be understood in terms of the overall Dungey model, modified by the expanding/contracting polar cap model, and the near Earth neutral line model. Substorms therefore involve both transient/localized signatures and also large-scale changes in the tail current sheet configuration and energization of the plasma. The THEMIS mission in particular was designed to study the chain of events that lead up to the triggering of a substorm (Angelopoulos et al. 2008) and more recent work on magnetospheric substorms and magnetotail dynamics has been reviewed by Sergeev et al. (2012).

Magnetospheric substorms are relevant for magnetospheric space weather because the reconfiguration of the magnetotail is associated with dynamic auroral emission-the auroral substorm (Akasofu 1964). An auroral substorm has a well-defined behaviour in space and time, which is directly associated with a reconfiguration of currents coupling the magnetosphere to the ionosphere, as well as the release of energy from the magnetotail, where it is stored in the magnetotail lobes.

There are several current systems that connect the magnetosphere and ionosphere (e.g. review by Milan et al. 2017). For example the region 1 field-aligned currents connect the magnetopause to the polar ionosphere, and hence define the open/closed field line boundary that is associated with the auroral oval (see Fig. 2). Region 2 field-aligned currents link the inner magnetosphere and the ring current to the ionosphere at lower latitudes. Field aligned currents are closed in the ionosphere by Pedersen currents in the auroral regions. During substorms, the magnetic field in the magnetotail near the Earth becomes more dipolar. This reduces the cross-tail current in a region transverse to the Sun-Earth line associated with the dipolarization. To ensure current closure, a so-called substorm current wedge is formed, whereby field aligned currents arise that connect the magnetotail with the ionosphere. This occurs in the expansion phase of the substorm. In the ionosphere a corresponding substorm electrojet forms. 
The strength of these current systems is often characterised using ground magnetic field measurements. For example, the AE index is commonly used to monitor substorm occurrence and strength. However, fixed measurement points on the ground cannot completely capture the properties of a dynamic auroral oval. The dynamics of these various currents systems that connect the ionosphere to the magnetosphere can now also be monitored by satellites and the associated deflection of the magnetic field. The Active Magnetosphere and Planetary Electrodynamics Response Experiment (AMPERE) used the engineering magnetometers from the Iridium satellite constellation to monitor on a global level the region 1 and region 2 Birkeland current pattern and its variability during substorms (Anderson et al. 2000, 2002; Clausen et al. 2013).

Geomagnetic storms arise when conditions conducive to dayside reconnection persist for long periods, leading to enhanced magnetospheric circulation, injection of energetic particles into the inner magnetosphere, and enhancements of both radiation belt fluxes and the ring current (Gonzalez et al. 1994). Coronal Mass Ejections and Corotating Interaction Regions are the two drivers of geomagnetic storm activity (Gosling et al. 1991; Richardson et al. 2001, 2006). To understand the severity and determine the occurrence rate of geomagnetic storms, different indices are used. Space weather forecast providers often characterise storm severity according to the $\mathrm{Kp}$ index $\left(\mathrm{Kp}_{\max }=9\right)$, which is designed to capture the severity of the global perturbation to the quiet magnetic field on the surface of the Earth (time resolution of 3 hours). Whilst the Kp index already rather coarse (not least in its measure of severity and its time resolution), for space weather end-users it is then translated into a five-step scale of severity from G1 to G5. The physical measure of a G5 event would be a $\mathrm{Kp}$ index of 9 and it is expected that there would be on average 4 such storm days per solar cycle.

On the other hand, in the scientific literature the Dst index is commonly used to measure the strength of geomagnetic storms, and is used to construct statistics about the severity of geomagnetic storms. Dst, which captures the strength of the ring current via its perturbation to the equatorial magnetic field on the surface of the Earth, provides information about the occurrence of geomagnetic storms on a global level, and therefore its statistics are a necessary part of understanding geomagnetic storm likelihood. The Dst index is usually near 0 , but during a storm it becomes negative. Dst $=-30$ to -50 is a weak storm, Dst $=$ -50 to -100 is moderate and Dst $<-100$ is considered intense (Gonzalez et al. 1994; Vasyliūnas 2011).

\subsection{Relevance of Substorms and Storms for Magnetospheric Space Weather}

As mentioned above in Sect. 2, it is the formation of GICs that are of primary concern for magnetospheric space weather. Geomagnetic storms are usually understood as the primary phenomenon that is considered relevant in this regard; hence the classification of space weather events used by NOAA and UKMO shown in Sect. 1. Much effort has been engaged in understanding the likelihood of a Carrington-class event based on geomagnetic storm indices (e.g., Love 2012; Riley 2012).

However, since geomagnetic indices reduce magnetospheric dynamics to a single number, although they may document occurrence, it is not clear that they adequately capture the likely impact (Hapgood 2011). In particular, based on even a crude understanding of the magnetospheric system, one can immediately deduce that GIC production is likely to be highly inhomogenous in both space and time, but organised to some extent by the location of the auroral oval and the substorm current wedge. In fact intense GIC events occur on regional scales, as shown by the analysis of geoelectric fields for 1 in 100 year scale events 
(Pulkkinen et al. 2015). Dst (and by extension Kp) must be used with caution (Kamide 2006) as unexceptional storms can nevertheless have notable impact, for example the storm of 4-5 August 1972 which had a Dst of -125 nT (Lanzerotti 1992). Furthermore, since it is an hourly index, Dst naturally smooths over many important details and arguably may hide both problems and physics that must be addressed to improve characterisation of space weather impacts.

It is increasingly recognised in the space weather community that current levels of magnetospheric space weather monitoring and warning, based on the global Kp index, are not fit for purpose, and better measures that more accurately define the threat to the power grid and other similar systems must provide localised, regional information. Therefore there is considerable current effort in developing forecasts that are capable of doing this (Pulkkinen et al. 2013). In particular, better physical understanding of the variation and severity of parameters such as the $\mathrm{AE}$ index, $d B / d t$ and the geoelectric field is required to fully understand space weather impact statistics.

This leads to a new perspective whereby in fact intense substorms provide the major space weather risk to power distribution networks, and whilst these may be associated with geomagnetic storms, they may also arise individually. Consequently, forecasting effort is also increasingly focused on improving the predictability of intense substorms at geomagnetic latitudes where power distribution systems are located. Since the precise relationship between geomagnetic storms and substorms is complex and still not well understood, this represents a current challenge to scientific understanding of magnetospheric space weather.

In this article we focus on the following 3 areas where better knowledge of the physical processes at work is key to improving magnetospheric space weather forecasting

- Transition from L1 to the magnetopause and the magnetosheath-i.e. the way in which the solar wind may evolve from L1 to the bow shock, and the way in which it is processed in the magnetosheath. Current knowledge and recent results are discussed in Sect. 3.

- Solar wind magnetosphere coupling - what is the physics that controls how solar wind plasma, momentum and energy all enter the magnetosphere? Where does this occur and on what timescale? This is examined in more detail in Sect. 4.1.

- Magnetotail energy release-formation of bursty bulk flows in the near Earth magnetotail that is associated with particle injection and auroral activity. Considerable progress has been made with spacecraft missions such as THEMIS and Cluster, discussed in Sect. 4.2.

All of these have an impact on the development of magnetospheric modelling and forecasting. This is examined further in Sect. 5.

\section{Input to the Magnetosphere: Solar Wind Driving and the Magnetosheath}

\subsection{Measuring the Inflowing Solar Wind}

The best location to measure the inflowing solar wind for operational magnetospheric space weather purposes is the L1 Sun-Earth Lagrange point. Historically, operational data has been provided by ACE (Stone et al. 1998) and is now provided by DSCOVR. A potential challenge associated with the measurement is that spacecraft in fact orbit around the L1 point, and so do not lie exactly on the Sun-Earth line. This may mean that simple models that convect the solar wind from the upstream measurement point to Earth may be incorrect because solar wind phase fronts are unlikely to be perpendicular to the flow (Collier et al. 
1998). Algorithms have been developed to account for this (e.g., Weimer and King 2008 and references therein) but different techniques can differ considerably in their prediction of transit time (Case and Wild 2012). A more accurate assessment of the solar wind conditions just upstream of the Earth is also made difficult by the fact that there can be variability in the solar wind perpendicular to the flow direction, that on large scales phase fronts are not planar and moreover that the solar wind evolves between L1 and the Earth (Kessel et al. 1999; Lepping et al. 2003; Tsurutani et al. 2005). Nevertheless, recent analysis shows that for operational modelling of the propagation delays from L1 to the Earth, interestingly there is no significant difference between the assumption of perpendicular and tilted solar wind phase fronts (Cash et al. 2016).

Before the solar wind actually reaches the magnetosphere, it first crosses the bow shock, which slows down the incoming supermagnetosonic flow to submagnetosonic speeds. Downstream of the bow shock, the magnetosheath plasma is denser, hotter, more turbulent, and exhibits stronger magnetic fields. The presence of the magnetosheath influences solar wind-magnetosphere coupling, since it is the magnetosheath plasma that interacts with the magnetosphere at the magnetopause.

\subsection{Influence of the Magnetosheath}

Firstly, it should be noted that the conditions observed in the solar wind are not necessarily representative of those encountered just upstream of the magnetopause. This may lead to an incorrect prediction of their impact on the magnetosphere. The IMF orientation can be significantly modified inside the magnetosheath (Coleman 2005; Longmore et al. 2006; Turc et al. 2014b). In particular, it has been shown that the magnetic field $\mathrm{Bz}$ component can have opposite signs upstream and downstream of the bow shock (Šafránková et al. 2009; Turc et al. 2017). This is exemplified in Fig. 4, which shows the Bz along the magnetopause for an IMF with a northward Bz, obtained from a magnetosheath model (Turc et al. 2014a). As evidenced by the blue areas, Bz turns south in some parts of the magnetosheath. This can in turn influence where reconnection occurs. The modification of the solar wind properties across the bow shock may also explain the saturation of the polar cap potential during strong magnetospheric driving. The polar cap potential is related to the solar wind electric field (and therefore Poynting flux) and is the potential difference across the open field line region in the ionosphere. Observationally, the polar cap potential is proportional to the solar wind electric field up to a certain limit where it then saturates, no longer responding linearly (e.g., Pulkkinen et al. 2016). Pulkkinen et al. (2016) show that in fact the ionospheric response correlates linearly with the Poynting flux normal to the magnetopause, whereas it saturates when compared to the solar wind Poynting flux. This suggests that the saturation is related to the processing of the solar wind through the bow shock and magnetosheath, and supports the fact that the conditions just upstream of the magnetopause are a better proxy of the magnetospheric driving.

It is also worth noting that the magnetosheath properties vary spatially. Many studies have shown evidence of pronounced dawn-dusk asymmetries in the magnetosheath parameters, such as the magnetic field strength and plasma velocity, the ion density and temperature (Dimmock and Nykyri 2013; Dimmock et al. 2015, 2016; Paularena et al. 2001; Longmore et al. 2005; Walsh et al. 2012). These asymmetries are due for the most part to the conditions encountered at the bow shock, and in particular to the angle $\Theta_{\mathrm{Bn}}$ between the IMF and the normal to the shock's surface, which is defined locally. This implies that the dawndusk asymmetries are associated with the Parker-spiral IMF, but that other IMF orientations would result in a different distribution of the magnetosheath parameters. In addition to the 
Fig. 4 Magnetic field $\mathrm{Bz}$ component along the magnetopause for a weakly northward IMF (Turc et al. 2014a) semi-analytical magnetosheath model based on ideal MHD

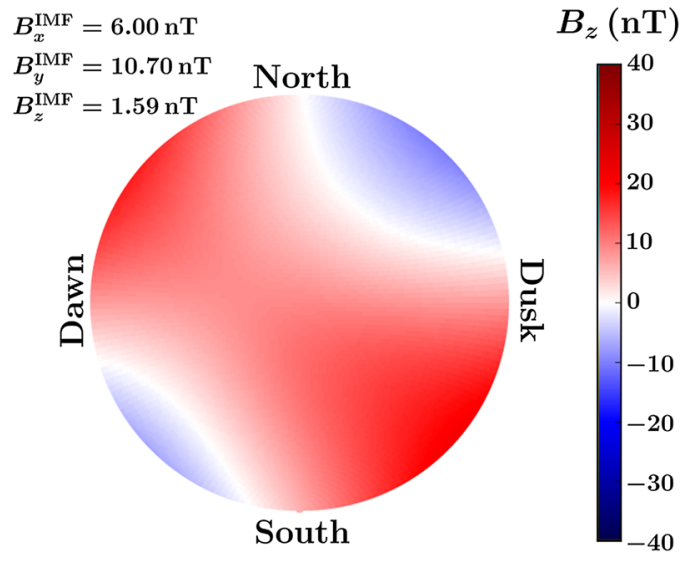

bow shock processes, the draping of the field lines along the magnetosphere also contributes to modifying spatially the magnetic field direction inside the magnetosheath. The spatial variation of the magnetosheath properties can affect the onset of magnetic reconnection and the development of the Kelvin-Helmholtz instability (e.g., Borovsky et al. 2008; Nykyri 2013).

Additionally, the bow shock and magnetosheath properties can be significantly modified during low Alfvén Mach number conditions, which are often associated with ICMEs and magnetic clouds. This may alter the solar wind-magnetosphere coupling during extreme space weather events (Lopez et al. 2004, 2011; Lavraud et al. 2007; Lavraud and Borovsky 2008; Farrugia et al. 2013; Turc et al. 2016).

\section{Magnetospheric Dynamics: Recent Observations and Current Understanding}

\subsection{Solar Wind Coupling at the Magnetopause}

At the magnetopause, the fundamental challenge for magnetospheric space weather forecasting is to understand when and where reconnection will occur, the physics by which reconnection occurs (so that it may be modelled accurately), and its temporal variability. It is also important to recognise other mechanisms transporting plasma across the magnetopause, specifically the Kelvin Helmholtz instability which may be important when the effects of magnetic reconnection are absent or reduced, for example during northward IMF conditions. We note that there are many recent reviews of both magnetic reconnection in space (e.g., Fuselier and Lewis 2011; Hesse et al. 2011; Eastwood et al. 2013; Paschmann et al. 2013) and the physics of the magnetopause (e.g., Lavraud et al. 2011; Hasegawa 2012; Eastwood et al. 2015b). Here we focus on aspects that are of importance for understanding magnetospheric space weather.

\subsubsection{Where and When Will Reconnection Occur?}

The concept of the open magnetosphere was cemented by the discovery of reconnection jets at the magnetopause by ISEE (Paschmann et al. 1979). Subsequent satellite measurements 
provided considerable experimental data, including measurements of oppositely directed exhausts either side of the X-line and extension of the X-line across a substantial fraction of the dayside magnetopause, i.e. the X-line extends out of the plane of Fig. 1 (Phan et al. 2000; Baker et al. 2002; Fuselier et al. 2002; Dunlop et al. 2011a, 2011b).

The extent of reconnection on the magnetopause fundamentally controls the coupling between the solar wind and the magnetosphere (Cowley and Owen 1989). Observations would appear to show that 'component' reconnection (i.e. reconnection where the magnetic shear across the magnetopause is less than $180^{\circ}$ ) prevails (Retinò et al. 2005; Trenchi et al. 2008; Dunlop et al. 2011a, 2011b). In component reconnection the magnetic field is decomposed into a guide field component and a reconnecting component. Models of X-line location which follow the location of maximum rotation in the field across the boundary match observations (Trattner et al. 2007a, 2007b, 2012). It should be noted that the modelling is made more complex by the fact that the local geometry varies with position on the curved magnetopause surface.

A further complicating factor is the asymmetry of the magnetopause: the different conditions on either side of the current sheet, in particular density, field strength and temperature (e.g., review by Eastwood et al. 2013 and references therein). An important result is the prediction that the $\mathrm{X}$-line and the stagnation point are separated if the reconnection is asymmetric (Cassak and Shay 2007). In combination with the guide field and flow shear this could alter when and where reconnection is likely to occur (Tanaka et al. 2010). The 'beta-shear' condition says that reconnection is suppressed for an increasingly wide range of magnetic shear angles as the change in plasma beta $(\Delta \beta)$ increases (Swisdak et al. 2003 , 2010), following earlier suggestions that magnetosheath plasma beta was a controlling factor (Paschmann et al. 1986). In particular, reconnection is predicted to be suppressed if $\Delta \beta$ is too large according to the following formula

$$
\Delta \beta>2\left(\frac{L}{\lambda_{i}}\right) \tan \left(\frac{\theta}{2}\right)
$$

Where $L$ can be considered as the width of the magnetopause, $\lambda_{i}$ is the ion inertial length and $\theta$ is the rotation of the magnetic field across the magnetopause. A small value of $\theta$ is equivalent to the statement that the guide field is large. This means that if $\Delta \beta$ is large (i.e. if the magnetosheath plasma beta is high, since the magnetospheric plasma beta is typically low), then reconnection will not occur if the guide field is too large. This relatively simple relationship may therefore be important in producing more refined analytic/empirical models of solar wind magnetosphere coupling, or could be introduced as a heuristic rule into models. This effect has been tested in the solar wind and at the magnetopause, and appears to be a good measure of reconnection occurrence (Phan et al. 2010, 2013). Figure 5a shows 49 magnetopause crossings where magnetic reconnection was observed. The majority of the data points are above the line which is the region where reconnection is not suppressed. In contrast, Fig. 5c shows 24 magnetopause crossings where no reconnection was observed. In these cases, the data points are predominantly below the line. Figures $5 \mathrm{~b}$ and $5 \mathrm{~d}$ show similar data but for events restricted in magnetic local time near the subsolar point, where the division in behaviour is even more apparent.

Finally a new area of work is the impact of magnetospheric plasma on reconnection at the magnetopause. In particular, plasmaspheric drainage plumes (caused by enhanced convection electric fields eroding the plasmasphere) can extend to the dayside magnetopause, where they influence reconnection and may reduce the reconnection rate (Borovsky et al. 


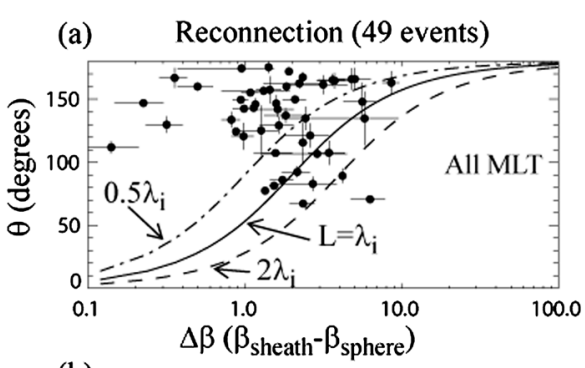

(b)

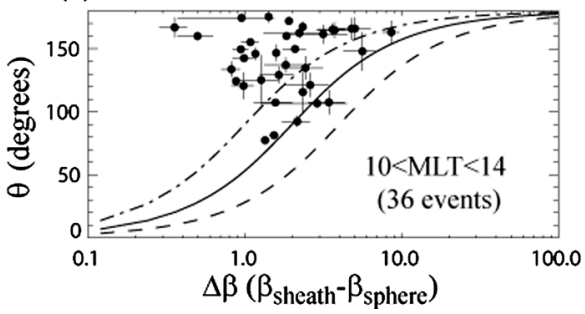

(c) Non-Reconnection (24 events)

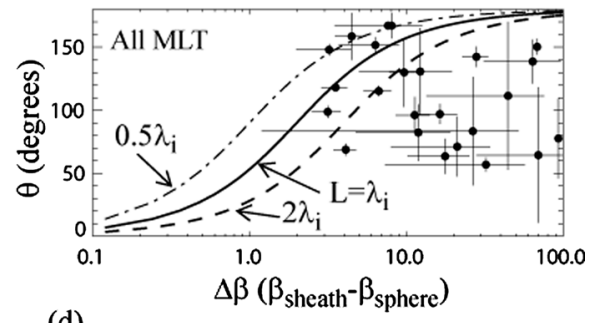

(d)

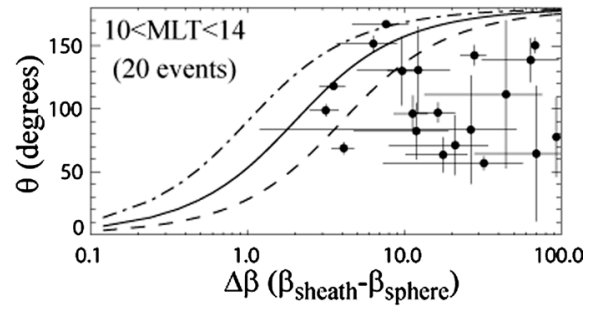

Fig. 5 (Adapted from Phan et al. 2013, Fig. 2; Copyright 2012 by the American Geophysical Union, reproduced with permission.) Results of a statistical survey of reconnection (left) and nonreconnection (right) events. (a, c) Scatter plot of magnetic shear versus $\Delta \beta$ across the magnetopause for all magnetic local time (MLT); (b, d) magnetic shear versus $\Delta \beta$ in the vicinity of the subsolar region $(10<$ MLT $<14)$

2013; Walsh et al. 2014). This suggests that it is important to account for these cold populations in modelling the solar wind magnetosphere coupling at the magnetopause for space weather forecasting purposes.

\subsubsection{Physics of Reconnection and the Diffusion Region}

Whilst magnetic reconnection has large-scale magnetospheric consequences, reconnection itself occurs within the small-scale diffusion region where the plasma decouples from the magnetic field and the frozen in field theorem no longer applies. In fact, the diffusion region is structured: because of their larger mass, the volume over which the ions are not frozen in (the ion diffusion region), is much larger than the electron diffusion region (EDR) where the electrons decouple and reconnection actually occurs. The length scales for these regions is roughly comparable to the relevant particle's gyroradius (or more precisely the inertial length) (Vasyliunas 1975). At the magnetopause the EDR region is only a few kilometres in size.

The physics of the diffusion region has been the subject of much recent investigation to understand precisely how the plasma and the magnetic field decouples. A key signature of the ion diffusion region which has received considerable attention is the formation of Hall magnetic fields due to the different motion of the ions and electrons (see e.g. recent reviews by Fuselier and Lewis 2011; Paschmann et al. 2013; Goldman et al. 2016). The structure and properties of the ion diffusion region has been resolved by spacecraft missions such as Cluster, Geotail and THEMIS which typically measure the plasma on timescales of a few seconds.

More recent observations from the Magnetospheric Multiscale mission (MMS) have focussed on the electron diffusion region (EDR). MMS is a four spacecraft mission (Burch et al. 2016a) and each spacecraft carries an identical payload of instruments to measure the 
electric and magnetic fields, the plasma population and composition, and energetic particles. In particular, the MMS fast particle instrument (FPI) can measure the electron and ion all sky distribution function at $30 \mathrm{~ms}$ and $150 \mathrm{~ms}$ resolution respectively (Pollock et al. 2016), meaning that it is able to probe in detail electron physics and the properties of the EDR. The first major success of the MMS mission has been to record multiple encounters with the EDR, and measure the properties of the electrons there. Prior to the launch of MMS it was suggested that crescent-shaped features should be expected to occur in the plane perpendicular to the magnetic field and MMS has shown that electron orbits in the vicinity of the EDR are coherent, being observed in multiple events (Hesse et al. 2014; Burch et al. 2016b; Burch and Phan 2016 and references therein). This new knowledge about diffusion region physics can help guide the development of new models and theory that accurately captures reconnection physics in the magnetospheric context.

\subsubsection{Temporal Variability of Reconnection and Transient Behaviour}

Whilst overall magnetic reconnection can be steady at the magnetopause, temporal variations are often observed. In particular, flux transfer events are bipolar signatures in the component of the magnetic field along the magnetopause normal (Russell and Elphic 1978). They are associated with reconnection, which produces the normal magnetic field component and various different models have been proposed to explain their production, including patchy reconnection, multiple $\mathrm{X}$-line reconnection and time-variable reconnection (Russell and Elphic 1978; Lee and Fu 1985; Scholer 1988; Southwood et al. 1988). Of these various production methods, multiple X-line reconnection has received recent attention, being observed in simulations and spacecraft data (Raeder 2006; Omidi and Sibeck 2007; Hasegawa et al. 2010; Oieroset et al. 2014; Pfau-Kempf et al. 2016).

Flux transfer events are therefore important in the context of magnetospheric space weather because they contribute to the transfer of solar wind plasma and energy into the magnetosphere. A key question in this regard is their magnetic topology. If they are connected to the magnetosphere at only one end, then they will indeed transport flux into the magnetotail. However, they may be connected to the magnetosphere at one end, both ends, or neither end. Consequently, flux rope topology is crucial to investigate, and evidence suggests that this may be highly complex (Pu et al. 2013). An alternative approach is to use multi-spacecraft observations of FTE geometry to constrain their shape, size and therefore formation mechanism (Fear et al. 2008, 2012). Together with analysis of FTE transport along the tail magnetopause (Eastwood et al. 2012), this may elucidate how FTEs contribute to flux transport and whether they possibly modulate the rate at which the magnetosphere reaches substorm onset conditions.

\subsubsection{Other Plasma Transport Mechanisms: The Kelvin-Helmholtz Instability}

It is important to recognise that other mechanisms contribute to the transport of plasma into the magnetosphere, in particular the Kelvin-Helmholtz instability. It arises in association with the large velocity shear on the flank magnetopause and causes magnetopause surface waves to steepen into vortices and break (Hasegawa et al. 2004). It will occur most easily if the field is perpendicular to the flow, and is therefore important for northward IMF conditions, although it has been observed for southward IMF as well (Hwang et al. 2011). In the nonlinear stage microscale instabilities or reconnection can occur, enabling plasma to be transported across the boundary; this is now being resolved by MMS (Eriksson et al. 2016; Stawarz et al. 2016). Ultimately, the KHI is important for space weather because it allows 
solar wind plasma to enter on the flanks during northward IMF and in fact mass transport across the magnetopause appears to be enhanced for northward IMF (Palmroth et al. 2006). Better quantification of the plasma transport rate from new measurements and simulations will improve knowledge of cold dense plasma sheet formation and magnetospheric 'preconditioning' prior to intervals of southward IMF driving geomagnetic activity.

\subsection{Magnetotail Dynamics}

Magnetic flux transport in the near Earth tail region is dominated by high-speed plasma flows called Bursty Bulk Flows (BBFs), which are considered to be the outflow of the near-Earth reconnection. Associated electromagnetic field disturbances transport energy closer in towards the Earth's inner magnetosphere, are responsible for energetic particle injection and also for enhanced auroral precipitation. These energetic particle signatures of intense substorms are identified as important space weather phenomena that lead to spacecraft anomalies such as surface charging and deep dielectric charging (Bodeau 2015; Loto'aniu et al. 2015).

Ongoing multi-point spacecraft measurements have significantly contributed to enhancing our understanding in this area from the ability to determine spatial gradients and temporal evolution to the non-adiabatic/adiabatic acceleration processes of the particles related to the transient electric fields. For example, observations by THEMIS and Cluster have enabled advances in our understanding of substorm dynamics and current sheet dynamics relevant to near-Earth magnetotail reconnection (e.g. reviews by Sergeev et al. 2012; Petrukovich et al. 2016). The newly launched MMS spacecraft have started to/will resolve the physical properties of near-Earth magnetotail reconnection and associated disturbances down to electron scales. Whilst there are a number of important physical processes occurring in the magnetotail (reconnection itself, current sheet instabilities, waves, turbulence, etc.) in the following section we highlight the interaction between the reconnection jet and the Earth's dipole region, as this leads to two tail phenomena that are key for magnetospheric space weather: energetic particle injection and auroral precipitation.

\subsubsection{Reconnection Jets, Bursty Bulk Flows, Dipolarization Fronts and Dipolarization Flux Bundles}

In recent years, a plethora of different terms have arisen to identify different features of magnetotail dynamics. Here we provide a brief summary:

- As mentioned above, Bursty Bulk Flows (BBFs) are high speed flows in the plasma sheet. Although their occurrence rate is low, BBFs contribute a significant part of the total magnetic flux transport in the near-Earth magnetotail (Angelopoulos et al. 1999; Schödel et al. 2001). BBFs have 10-min time scales, with embedded velocity peaks of 1-min duration, which are called flow bursts (Baumjohann et al. 1989; Angelopoulos et al. 1992). They are localized in the dawn-dusk direction with scales of about 1-5 RE (Sergeev et al. 1996; Angelopoulos et al. 1997; Nakamura et al. 2001, 2004).

- The Dipolarization Front (DF) is a thin (ion scale, about 800-2000 km) boundary often observed on the leading edge of a BBF where the Bz component sharply increases (Nakamura et al. 2002).

- The Dipolarization Flux Bundle (DFB) (Liu et al. 2013) corresponds to the entire Bz enhancement following the DF. 
The most popular model describing flow burst/BBFs and their connection to the ionosphere is the plasma bubble model, where flow burst is a plasma-depleted and dipolarized magnetic flux tube (Pontius and Wolf 1990). Multipoint spacecraft measurements have observed the Earthward propagation of the DF from the midtail to the near-Earth region (Runov et al. 2011). As it propagates Earthward flux piles up and tailward pressure gradient force develops that leads to braking of the flows in the near-Earth dipolar region (Panov et al. 2010). In the flow braking region both the Earthward propagating dipolarization front and subsequent tailward progressing dipolarization can be detected (Nakamura et al. 2009). The plasma bubble model predicts that the bubble penetrates Earthward until the flux tube plasma content matches with that of the ambient dipolar magnetic field, a prediction observationally confirmed by statistical study (Dubyagin et al. 2011). Tailward flow bouncing and oscillatory signatures were also reported in this region indicating that the flow braking is a dynamic process (Panov et al. 2013a, 2013b).

The combined Flow bursts/DF/DFB entity can be regarded as a region of enhanced electric field so that different ions and electrons in the plasma sheet, depending on their pitch angle and energy can enter this region (or, alternatively, enter as the dipolarization front passes the ambient plasma region) for a limited time in a localized region of space as the front propagates Earthward, and are accelerated accordingly. Such a concept of an Earthward propagating electric field pulse has been considered as a source mechanism of injection (Quinn and Southwood 1982; Li et al. 1993). Recent multi-point spacecraft observations have allowed the physical processes around the boundary to be revealed in a more quantitative way. Since the dipolarization front thickness is usually ion-scales (typically less than 5 ion inertial lengths or 3 ion gyroradii) or even smaller, the Hall-electric field and the electronpressure gradient play a role in forming the front structure and 1-2 electron inertial length structure dominates the dissipation at the front (Fu et al. 2012; Angelopoulos et al. 2013; Balikhin et al. 2014).

Not all, but a large fraction of the fronts were shown to be tangential discontinuities meaning that at least for those boundaries the dipolarization front is simply a thin boundary dividing two different plasma regions (tenuous, hot BBF plasma and denser, colder ambient plasma) without net bulk flow across the boundary (Schmid et al. 2011). Particles that are trapped in the collapsing field line of BBF/DFB can gain energy from Fermi/betatron acceleration as was simulated and observed behind the dipolarization front (Ashour-Abdalla et al. 2011; Fu et al. 2012; Birn et al. 2013). On the other hand, other cases of dipolarization fronts were reported in which ambient ions are passing the front layer, accelerated by the electric field at the dipolarization front and then reflected back ahead of the front (Zhou et al. 2014; Eastwood et al. 2015a). While the occurrence of rapid flux transport rate observations significantly drops between 10 to $15 \mathrm{Re}$ (Schödel et al. 2001), the dipolarization front grows (Bz amplitude increases) closer in to the Earth, and a large dawn-to-dusk electric field in the flow braking region is both predicted from simulations and reported from observational studies (Birn et al. 2011; Liu et al. 2014; Schmid et al. 2016). Energetic particle injections accompanied by DFBs that were found from the midtail reconnection region $(30 \mathrm{Re})$ to inside geosynchronous orbit also suggest the importance of the transient/localized electric field enhancements of BBF and flow braking for the particle acceleration process (Gabrielse et al. 2014; Liu et al. 2016).

Note that the total energy gained from this process is, however, limited by the strength of the dawn-to-dusk (induced) electric field and the width of the dipolarization front. For a typically localized dipolarization front case, the above mechanisms explain acceleration of few $\mathrm{keV}$ to hundreds of $\mathrm{keV}$ for electrons, and a few tens of $\mathrm{keV}$ to hundreds of $\mathrm{keV}$ for protons (Birn et al. 2013). These particles are considered as the seed population of the radiation belt 
particles that are subsequently further accelerated by different mechanisms such as by waves in the inner magnetosphere. Recent observation of a global injection front accompanied by $\mathrm{MeV}$ particles detected inside 4 Re during storm time conditions (Dai et al. 2015), indicates that the maximum energy may be enhanced during those active events. Such observations suggest that for an intense substorm case, $\mathrm{DF} / \mathrm{DFB} / \mathrm{BBF}$ related acceleration may also contribute significantly to particle acceleration in the inner magnetosphere/radiation belt.

\subsubsection{BBF Size and Magnetotail Flux Transport}

From considerations of global flux balance (lobe flux reduction and associated closed flux transport), it is required that BBF should have an effective dawn-dusk size of about $10 \mathrm{RE}$ (Angelopoulos et al. 2013). This is larger than is typically observed. Large-scale size in the azimuthal direction is also expected from the size of the substorm current wedge. Furthermore, a typical time-scale for the substorm expansion phase is about 30 minutes, which is again longer than that of typical DFBs. How then do BBF/DF/DFB/flow bursts, that are shown to be transient in time and localized in size in a number of statistical studies, contribute to the larger scale evolution of the magnetosphere during substorms? One explanation is that large-scale substorm effects are the integrated effects of multiple BBFs that take place in space and time. Multiple flow bursts and associated auroral precipitation (so called auroral streamers, e.g., Kauristie et al. 2003) have been considered as supporting evidence for this. (Temporal and spatial relationships between these BBF-associated field-aligned currents and the substorm current wedge are further discussed by Kepko et al. 2015.) Although only for a limited number of cases, multipoint studies have shown evidence for a dipolarization front extended to $10 \mathrm{RE}$-scale during an intense substorm in the flow braking region and during storm time intense substorm in the inner magnetosphere (Nakamura et al. 2013; Dai et al. 2015). The longer time-scale of the substorm current wedge or auroral electroject as compared to BBFs/DFBs, on the other hand, could also be due to the accumulated effects of the flow bursts that modify the pressure distribution in the inner magnetosphere and thereby sustain the substorm current wedge (Kepko et al. 2015). In such cases the substorm time-scale would correspond to the time-scale of the pressure redistribution process that is expected to be longer than the BBF time scale.

\subsubsection{The Effects of Preconditioning on Magnetotail Dynamics}

Magnetotail disturbances are modified by both the preconditioning of the magnetotail and the solar wind driver. In this section we briefly overview the characteristics of the magnetotail for different density/temperature conditions and two different magnetospheric states: steady magnetospheric convection (SMC), and geomagnetic storms. Not only the background magnetic field configuration, such as the location of the thin current sheet, but also the plasma properties, such as plasma density and temperatures, are important factors for determining the magnetotail disturbance as well as the magnetosphere-ionosphere coupling. Sergeev et al. (2014) showed that the solar wind electric field is associated with a larger auroral electrojet when the plasma sheet is hotter and has lower density than for the colder and denser plasma sheet. This difference could be due to stronger fieldaligned acceleration of precipitating electrons for higher temperature and lower density as expected from Knight's relationship (Knight 1973). The hot, low density plasma sheet is expected to be produced by the lobe plasma entering and heating by reconnection. On the other hand, the source of the cold and dense plasma sheet is thought to be the solar 
wind/magnetosheath plasma entering from the flank, as discussed in Sect. 4.1.4. The processes responsible for the entry are diffusion at the low latitude boundary layer, mixing of plasma due to Kelvin-Helmholtz instabilities and associated reconnection, and poleward-ofcusp reconnection during northward IMF Bz (Song and Russell 1992; Terasawa et al. 1997; Hasegawa et al. 2004). It is important to note that although the response time of the reconnection process is less than 1 hour, the mixing process of cold-dense plasma sheet from the flank can take longer ( $>3$ hours).

Although minor in the number density, the effect of ionospheric heavy ion outflow can further contribute to changes in the time scale (slowing) and changes in the spatial scale of the current sheet due to larger inertial scales (see Kronberg et al. 2014 for more detail regarding the effects of heavy ions on magnetospheric processes). Hence, for understanding the solar wind-magnetosphere-ionosphere coupling, the background plasma conditions of the magnetosphere, produced by the different mechanisms of solar wind-magnetosphere interaction, as well as the ionosphere need to be taken into account. In particular, since the response time scales of these different processes to the solar wind drivers are different, that places significant constraints in predicting the magnetospheric response based on modeling.

The general effect of larger dawn-to-dusk solar wind electric field, created by southward IMF, is to move the near-Earth reconnection region closer to the Earth (Nagai et al. 2005). However, the response of the magnetotail to southward IMF conditions also depends on the nature of the preconditioning and the mode of magnetosphere-ionosphere coupling can differ from the simple substorm cycle discussed before, such as during steady magnetospheric convection (SMC). During SMC the enhanced, stable convection, persists longer than a typical recovery phase, with no substorm expansions (Pytte et al. 1978). The average total pressure in the inner magnetosphere is higher during SMC events than for other types of activity (Kissinger et al. 2012). This higher pressure region extends to larger radial distances, and causes fast Earthward flows to divert toward the dawn or dusk flanks and continue to the dayside leaving the inner magnetosphere relatively quiet.

This pattern of flux transport is in contrast to substorms, during which flows are directed toward the inner magnetosphere. The most extreme case of southward IMF Bz is the stormtime substorm, when significant loading of the magnetotail leads to: the reconnection site moving closer to Earth; enhanced ionospheric outflows causing a significant population of oxygen in the tail current sheet configuration; and $\mathrm{MeV}$ injection fronts observed inside 5 Re (Baumjohann et al. 1996; Miyashita et al. 2005; Kistler et al. 2006; Dai et al. 2015; Baker et al. 2016). The mode of the magnetotail disturbance, therefore, can be significantly different depending on the different level of IMF southward and resultant preconditioning of the magnetotail.

\section{Modelling and Predicting Magnetospheric Space Weather}

As discussed in the previous sections, the processes that cause adverse magnetospheric space weather effects are largely a consequence of solar wind-magnetosphere coupling. Although the processes at work encompass a wide range of spatial and temporal scales, significant success in understanding magnetospheric physics has been received through the use of computer simulations that employ magnetohydrodynamic-based codes. These simulations solve the equations of MHD on a 3-dimensional grid that encompasses the whole magnetosphere. This has the advantage of efficiently describing the large scale structure of the magnetosphere, the transport of plasma, and the coupling between different regions. Large scale communication is accomplished via MHD waves-i.e. magnetosonic and Alfven waves. 


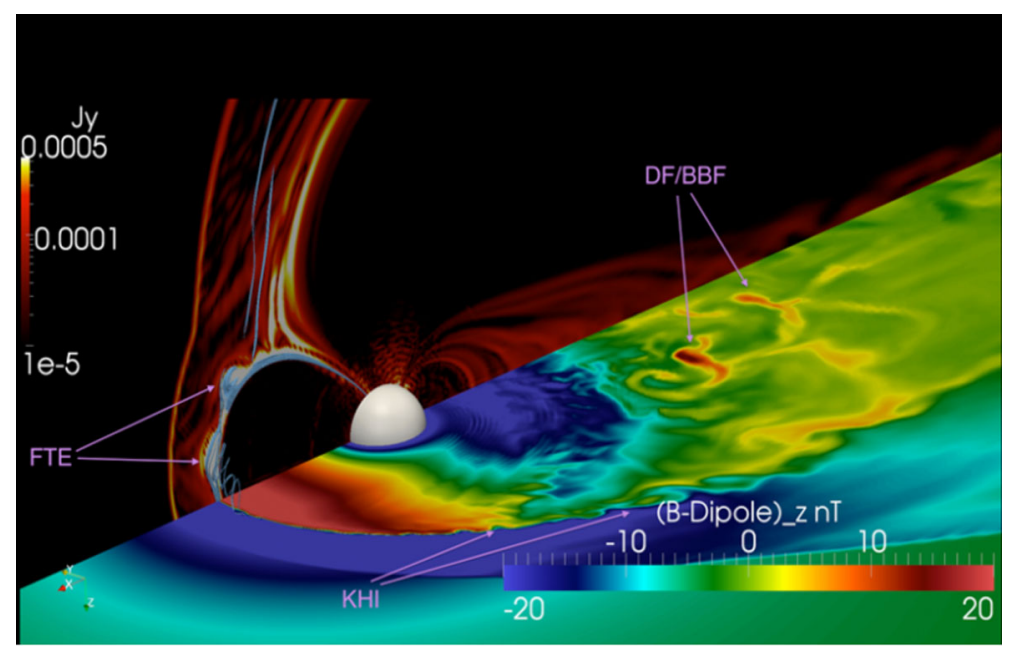

Fig. 6 Lyon-Fedder-Mobarry global magnetosphere model showing flux transfer events (FTEs) at the dayside magnetopause, dipolarization fronts (DFs) and bursty bulk flows (BBFs) in the magnetotail, and Kelvin-Helmholtz instability (KHI) at the flank of the magnetosphere. Color contours show the dawn-to-dusk current $(\mathrm{Jy})$ in the noon-midnight $(\mathrm{X}-\mathrm{Z})$ plane and northward magnetic field $(B z)$ in the equatorial $(\mathrm{X}-\mathrm{Y})$ plane (from Sitnov et al. 2016)

They also capture large scale current systems, however, we note that codes typically use the ' $\mathrm{v}$ B' approach (as opposed to 'E J') (Vasyliunas 2005), and the current is derived from the curl of the magnetic field. The size of the simulation domain is typically sufficient to include the inflowing solar wind and the magnetotail, and the magnetosphere is modelled as a whole, from the solar wind input at the sunward edge to an inner boundary (usually at $2 \mathrm{RE}$ to $5 \mathrm{RE}$ ), and then to the magnetotail. So-called global MHD simulations (GMHD) have been available for a number of years, and have become increasingly popular given the recent increase in affordable computing power. An example of such a simulation is shown in Fig. 6.

\subsection{Global Modeling}

GMHD codes used to simulate the Earth's magnetosphere include: the Open Geospace General Circulation Model (OpenGGCM), the Block-Adaptive-Tree-Solarwind-Roe-UpwindScheme (BATS-R-US), the Grand Unified Magnetosphere-Ionosphere Coupling Simulation (GUMICS) and the Lyon-Fedder-Mobarry (LFM) model (Powell et al. 1999; Lyon et al. 2004; Raeder et al. 2008; Janhunen et al. 2012). It is important to note that given the complexity of the magnetosphere, these simulations in fact form one component of a more complex modelling architecture. In all cases, the core GMHD code must be coupled to a module capable of capturing the ionospheric (and thermospheric) dynamics via field aligned currents. For example the Coupled-Magnetosphere Ionosphere Thermosphere (CTIM) model, the Thermosphere-Ionosphere-Electrodynamic Global Circulation Model (TIEGCM) and the Magnetosphere Ionosphere Coupler Solver (MIX) are used in conjunction with LFM (Roble and Ridley 1994; Wang et al. 2004; Wiltberger et al. 2004; Merkin and Lyon 2010). OpenGGCM is also used with CTIM. BATS-R-US is used with the Rice Convection Model and the Ridley Ionosphere Model as part of the Space Weather 
Modeling Framework (SWMF), which brings together simulation models ultimately capable of capturing the whole chain of space weather physical processes between the Sun and the Earth (Wolf et al. 1982; Toffoletto et al. 2003; Ridley et al. 2004; Toth et al. 2005, 2012). Despite the growing complexity of these codes, it is of course acknowledged that they do not contain all the relevant physics. In addition, capturing the onset of magnetotail reconnection leading to a substorm may well depend on numerical resistivity, which arises from small inconsistencies in the calculation due to rounding errors. Furthermore, instabilities will not be correctly described at the most fundamental level. Although code-coupling attempts to adequately describe the inner magnetosphere, radiation belts and ionospheric outflow, this is not without its own difficulty or complexity, and this remains a current challenge (Eastwood et al. 2015b). Nevertheless, GMHD simulations are widely used since they can run in real time with current computational resources, and they provide a route to a first-principle physics-based model of substorms. It is also possible to derive magnetospheric diagnostics relevant for space weather, such as: the size of the auroral oval and polar cap boundary; the location and shape of the magnetopause; and upper atmospheric heating (by calculating Joule heating) (Gordeev et al. 2015). Furthermore, they can in principle be used to predict the ground $d B / d t$ which is crucial for space weather forecasting in the magnetosphere (discussed in more detail below) (Pulkkinen et al. 2013).

The utility of these simulations is therefore multi-faceted. Firstly, they enable exploration of the basic physics that controls magnetospheric dynamics; here we mention a few illustrative examples: the analysis of Palmroth et al. (2006) using the GUMICS code elucidated the fact that mass transport across the magnetopause may be enhanced for northward IMF; investigating the magnetospheric drivers and energy input under different IMF conditions (Raeder et al. 2001; Palmroth et al. 2003; Pulkkinen et al. 2007; Sergeev et al. 2008; Yu and Ridley 2009); exploring the temperature asymmetry in the magnetosheath under different solar wind conditions (Dimmock et al. 2015); modelling the effects of shocks on the magnetosphere (Andréeová et al. 2008; Oliveira and Raeder 2014); and performing large scale statistical studies (Juusola et al. 2014; Facskó et al. 2016).

Secondly, they can be used to provide large scale context and interpretation of sparse in situ spacecraft measurements (e.g., Raeder et al. 2008). This is a research approach that has proved particularly fruitful, to the extent that the Community Coordinated Modeling Center (CCMC) at NASA's Goddard Space Flight Center now provides simulation runs on demand to the general space physics community (MacNeice et al. 2012). The growth of the CCMC in particular has stimulated the use of these codes as a general tool that can be employed by scientists outside the core development team, rather like how spacecraft data is now easily used by scientists who are not part of the instrument team. Specific examples of this approach are numerous and we refer the reader to the CCMC website. ${ }^{1}$

\subsection{Benchmarking and Forecast Accuracy}

GMHD models are being transitioned into the operational domain for the purposes of space weather modelling and forecasting (Pulkkinen et al. 2010). In doing this, it is necessary to have confidence that the models and simulations are sufficiently accurate and this can be achieved through the use of appropriate metrics (e.g., Lopez et al. 2007). A recent example of this is the benchmarking performed by Gordeev et al. (2015). In this paper, several key global variables were identified which as well as characterising the global magnetosphere, are potentially relevant for space weather forecasting. The first set of metrics concern the

\footnotetext{
${ }^{1}$ https://ccmc.gsfc.nasa.gov/.
} 
Table 1 Summary of skill scores for four different GMHD models, adapted from Table 3 of Gordeev et al. (2015; Copyright 2015 by the American Geophysical Union, reproduced with permission). The slope and CC (correlation coefficient) refer to the gradient and uncertainty of the best fit line when a regression is performed against the relevant empirical model. The PE (prediction efficiency) is a measure of the forecast skill. In all cases, values equal to unity indicate accurate performance. Grey boxes highlight the best performing model for each metric, according to the correlation coefficient

\begin{tabular}{|c|c|c|c|c|c|c|c|c|c|c|c|c|}
\hline \multirow[t]{2}{*}{ Parameter } & \multicolumn{3}{|c|}{ BATS-R-US } & \multicolumn{3}{|c|}{ GUMICS } & \multicolumn{3}{|c|}{ Open GGCM } & \multicolumn{3}{|l|}{ LFM } \\
\hline & Slope & $\mathrm{CC}$ & PE & Slope & $\mathrm{CC}$ & PE & Slope & $\mathrm{CC}$ & PE & Slope & $\mathrm{CC}$ & PE \\
\hline Subsolar m'pause & 1.01 & 0.95 & +0.88 & 0.96 & 0.85 & +0.31 & 0.90 & 0.77 & -1.47 & 0.92 & 0.91 & -0.43 \\
\hline Terminator m'pause & 1.03 & 0.64 & -0.02 & 0.97 & 0.93 & +0.62 & 1.11 & 0.47 & -3.20 & 1.00 & 0.44 & -0.95 \\
\hline Tail Mpause & 1.03 & 0.77 & +0.22 & 0.93 & 0.80 & -0.55 & 1.13 & 0.73 & -3.19 & 0.99 & 0.73 & -0.04 \\
\hline Tail B field & 0.83 & 0.95 & +0.49 & 0.75 & 0.94 & +0.01 & 0.93 & 0.97 & +0.86 & 0.78 & 0.86 & +0.02 \\
\hline Field aligned currents & 0.37 & 0.86 & -0.44 & 0.05 & 0.48 & -2.15 & 2.01 & 0.68 & -5.15 & 0.98 & 0.93 & +0.87 \\
\hline
\end{tabular}

size of the magnetosphere, as defined by the distance to the subsolar magnetopause, and the radius of the magnetosphere at the terminator and $15 \mathrm{RE}$ downtail. The second set of metrics is focussed on the magnetotail, its pressure balance and its magnetic flux content. These are defined by the plasma sheet thermal pressure and the lobe magnetic field. The remaining metrics are related to magnetospheric dynamics and substorms, and include the polar cap potential drop (to capture the rate of global convection), the total field aligned current, and more recently in Gordeev et al. (2017), the extent to which substorm loading occurs. Each of these can be validated against an empirical model, such as the Shue et al. (1998) magnetopause model in the case of the distance to the sub-solar magnetopause.

Gordeev et al. (2015) then defined a series of standard solar wind inputs, with densities, temperatures and velocities consistent with the statistical properties of the solar wind. In this study, 19 different synthetic solar wind profiles were identified, of 4 hour duration. The initial two hours contained northward IMF, which may then vary according to the specific run. These input conditions were applied to four models running at the CCMC-OpenGGCM, GUMICS, BATS-R-US and LFM. The output was analysed at 5 minute resolution, and various metrics such as the prediction efficiency were computed (Pulkkinen et al. 2011).

This analysis reveals that different models have different strengths and weaknesses. For example, the BATS-R-US model is found to best agree with empirical models of the subsolar magnetopause location, as shown in Fig. 7. On the other hand, the high-latitude tail magnetopause is best captured by GUMICS. The strength of the lobe field is most accurately predicted by the OpenGGCM simulation, and the LFM model is best performing against the field-aligned current metric. Table 1 below reproduces a summary of the results.

Gordeev et al. $(2015,2017)$ note that in fact all four models perform reasonably well and capture at least in a qualitative sense the correct behaviour that is expected to be observed for a given change in solar wind conditions. However, this analysis highlights the fact that although simulations are, thanks to CCMC, now available 'on demand', their use and interpretation requires care and expert insight into the nature of the code itself. Furthermore, it raises the potentially important point that the choice of model to be used for space weather forecasting may depend on the purpose for which the forecast is required. For example, the real-time modelling of the magnetopause location is important to predict whether it moves within geostationary orbit. Spacecraft charging will be altered in the higher density plasma of the magnetosheath and furthermore the magnetic field orientation will change, which could affect older spacecraft that use the magnetic field as part of their Attitude and Orientation Control System (AOCS). 
(a)

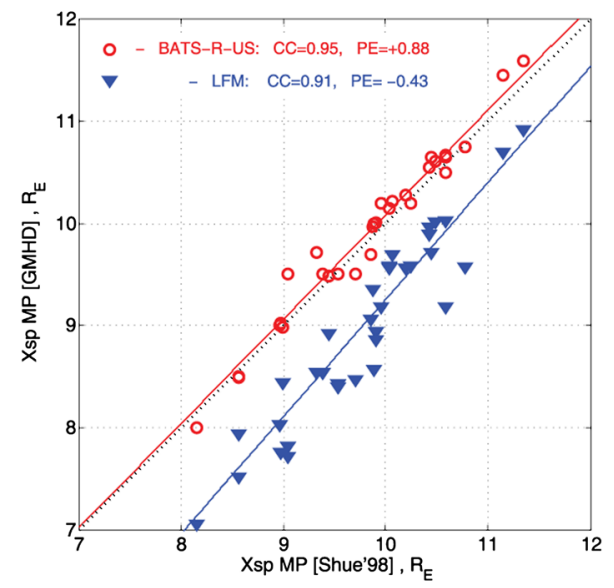

(c)

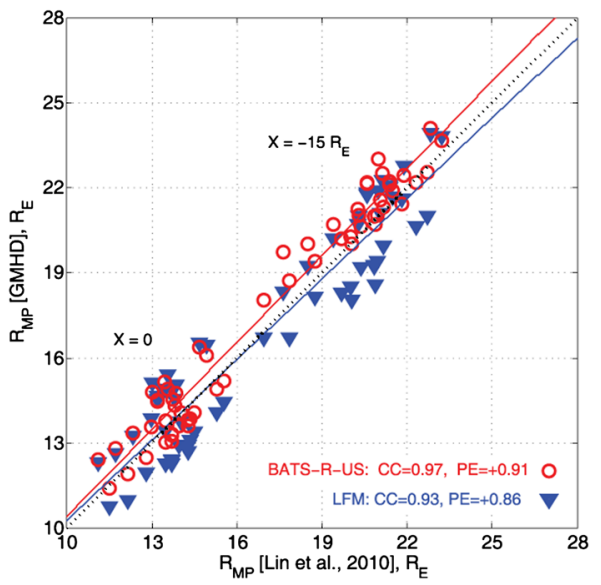

(b)

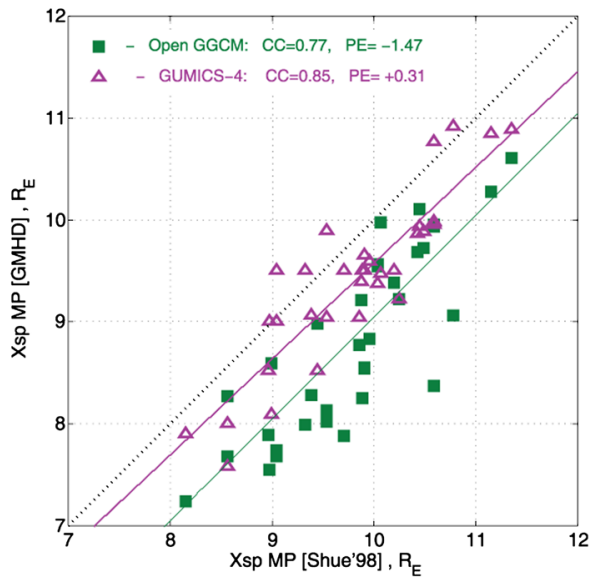

(d)

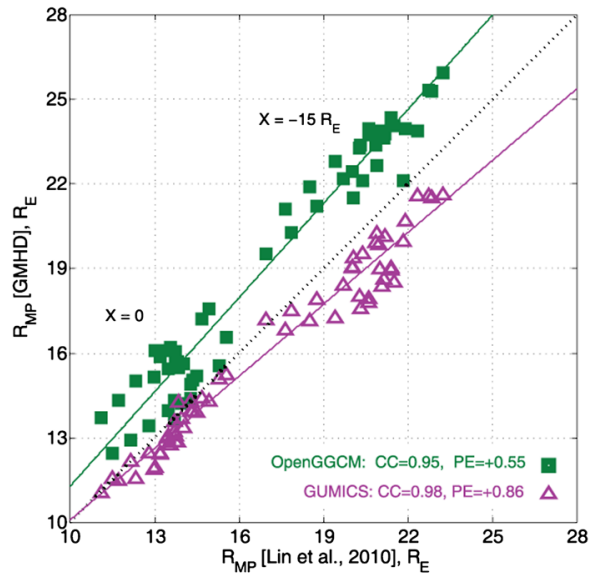

Fig. 7 (a-b) The performance of different GMHD models in identifying the location of the subsolar magnetopause, as benchmarked against the Shue et al. (1998) empirical magnetopause model. It is found that in this test, the BATS-R-US code is best performing. (c-d) Comparable plots for the combined location of the high-latitude terminator and tail magnetopause. Separate analysis of these two regions is shown in Table 1. (Figure adapted from Gordeev et al. 2015; Copyright 2015 by the American Geophysical Union, reproduced with permission.)

As explained above, the most important parameter for space weather modelling is $d B / d t$, the rate of change of the magnetic field on the ground. The ability of different magnetospheric models to predict this parameter has been specifically analysed by Pulkkinen et al. (2013). They identified 6 baseline geomagnetic storm events including the 2003 Halloween storms. For these events, the driving solar wind data from L1 was available, as were measurements of $d B / d t$ on the ground at 12 geomagnetic observatories. Three different global MHD models were evaluated: LFM-MIX, OpenGGCM, and the SWMF and were also compared with two empirical models. In each case, the L1 data were used to drive the simulations, and the ground magnetic field perturbation was predicted at 6 of the magnetometer stations. The simulations were all performed at CCMC. The simulation/modelling outputs were then 


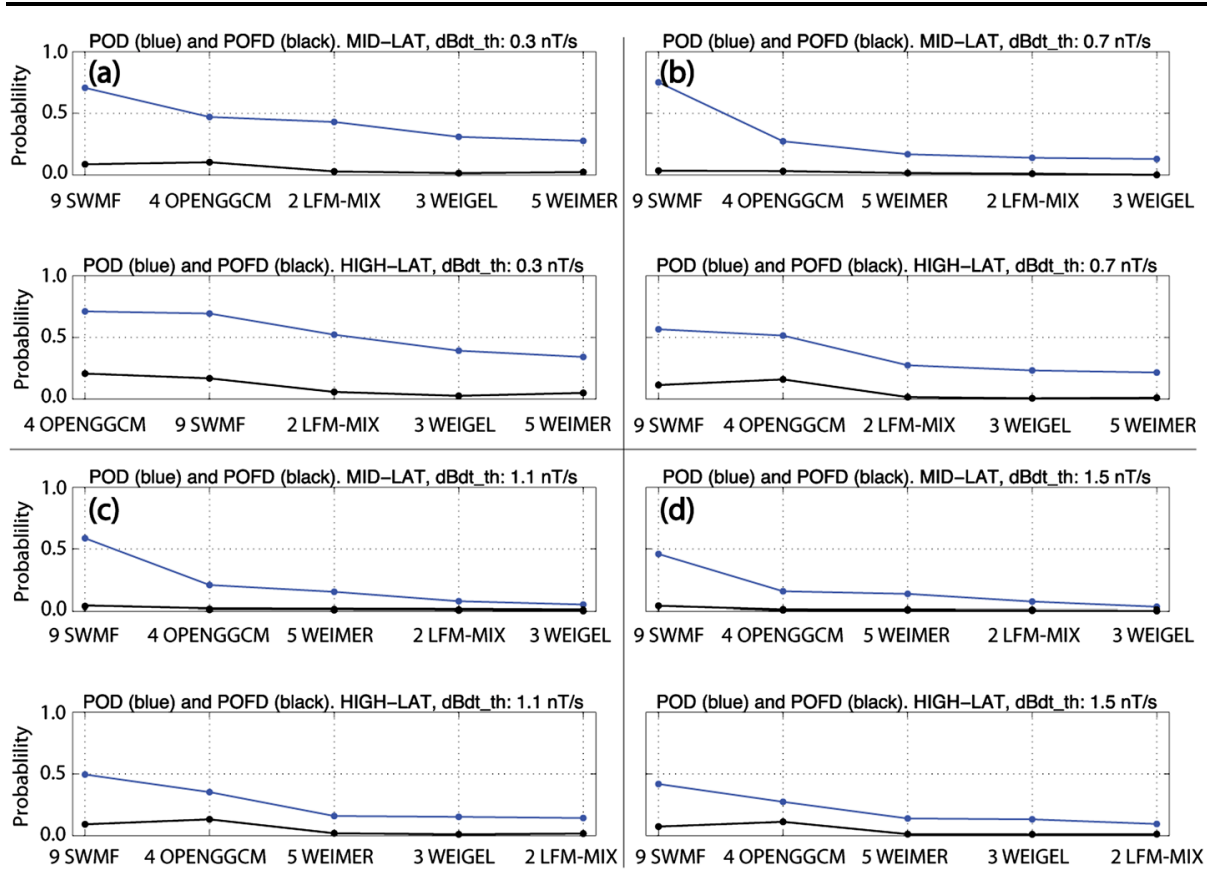

Fig. 8 The probability of detection and probability of false detection of $d B / d t$ is shown for different $d B / d t$ thresholds, at high- and mid-latitudes (adapted from Fig. 5 of Pulkkinen et al. 2013; Copyright 2013 by the American Geophysical Union, reproduced with permission)

compared to the observed data using a series of different metrics. These were the probability of detection (POD), the probability of false detection (POFD) and the Heidke Skill Score (HSS; $1 \geq$ HSS $>-\infty$ ). If HSS $=0$ then the prediction is as good as random, and if $\mathrm{HSS}=1$ then the prediction is perfect (Lopez et al. 2007). A score of 0.5 therefore indicates a $50 \%$ chance of event detection. Example results are shown in Fig. 8 which shows the POD and POFD of $d B / d t$ by different models and simulations. The data is split according to the location of the measurement on the ground (high- and mid-latitude) and the strength of the $d B / d t$ signal $(0.3,0.7,1.1$ and $1.5 \mathrm{nT} / \mathrm{s})$. It can be seen that in general the SWMF is on average the best performing according to this metric. However, it was found that the POD and HSS was less than 0.5 for a $d B / d t$ threshold of $1.5 \mathrm{nT} / \mathrm{s}$. Nevertheless, it was concluded by Pulkkinen et al. (2013) that "users satisfied with more rough characterisation of $d B / d t$ activation over the storm periods may be able to use the models for generating actionable information."

\section{Future Developments}

\subsection{Future Developments: Spacecraft Measurement}

Spacecraft measurements for magnetospheric space weather forecasting can be divided into two types. On the one hand, data is required to advance understanding of the underlying physics. In this regard, at the time of writing MMS is primed to make considerable progress. The combination of multiple operating missions (Cluster, Geotail, MMS, THEMIS, etc.) 
allows the magnetosphere to be studied more comprehensively. Outstanding problems relevant for space weather prediction include: how to accurately translate L1 data to the subsolar magnetopause; how to accurately model the location, onset, duration and variability of magnetopause reconnection; how to adequately capture magnetospheric preconditioning; how to include multiscale processes, both temporal and spatial, in magnetotail models; and to understand where, when and how magnetotail reconnection starts and evolves, to establish whether localized plasma jets are due to localized reconnection or locally evolved structure, and whether multiple activations are spatial or temporal in nature. Nevertheless, the measurements are sparse, and this represents a major obstacle to progress in magnetospheric physics as a whole. So-called constellation missions represent an obvious next step forward and an intriguing possibility is to use CubeSat platforms (Spence et al. 2001, 2004; Schwartz et al. 2009; Eastwood 2015). This would be complemented by missions that exploit remote sense. One potentially transformative idea is to remote sensing the outer magnetospheric boundaries through soft X-ray charge exchange (Branduardi-Raymont et al. 2012), which is the goal of the ESA/CAS SMILE mission.

The other activity pertains to operational monitoring, by platforms which provide measurements to be used in operational space weather forecasting. This is likely to make use of dedicated platforms - for example DSCOVR at L1, and GOES in GEO. Improving lead times for magnetospheric space weather monitoring requires measurements to be made in the solar wind further upstream than L1. This could be achieved with a solar sail mission or inner heliosphere measurements (Eastwood et al. 2015c; Kubicka et al. 2016). Within the magnetosphere, improving the density of measurements can also be achieved by using hosted payloads. An example of this within the ESA space situational awareness programme is SOSMAG which will be hosted on GEO-KOMPSAT-2A (Auster et al. 2016).

\subsection{Future Developments: Modelling and Forecasting}

At the time of writing, NOAA's Space Weather Prediction Center is using the SWMF model operationally. ${ }^{2}$ In the future, the availability of multiple magnetospheric models at the operational level is desirable to provide diversity of forecast methodology. Linked to this is the use of ensemble forecasting (Knipp 2016); this requires the ability to run predictions faster than real time. Finally, another option for improving forecasts would be to perform data assimilation, but this is challenging because of sparse measurements in the magnetosphere.

Looking to the future, modelling of strong storms requires a change in grid step, and changes in the treatment of the inner boundary because of the movement of the dayside magnetopause towards the Earth. Another challenge is the development of appropriate metrics to test models in a relevant way. For example, this may mean the use of operational metrics designed specifically for certain forecast types or user communities, and not simply science-based assessments. In the context of the work discussed here, such a metric may correspond to GIC threshold, rather than polar cap potential for example.

A key question in the medium term future is the issue of developing models that deliver forecasts of improved accuracy. In some sense this is already in progress, with the standard approach of coupling different codes that describe different regions (notably the ring current, the plasmasphere and the ionosphere/thermosphere system). One route is to include reconnection physics by modifying the treatment of resistivity, or to embed PIC simulation capability within the larger fluid simulation (Kuznetsova et al. 2007; Tóth et al. 2016). A global Vlasov code has been developed-Vlasiator (Sandroos et al. 2013; von Alfthan et al. 2014;

${ }^{2}$ http://www.swpc.noaa.gov/products/geospace-global-geomagnetic-activity-plot. 
Kempf et al. 2015) and this may ultimately be the simulation tool of choice, as computing power becomes sufficiently powerful and accessible. This may enable a more detailed exploration of the Axford conjecture, which argues that large-scale magnetospheric dynamics are governed by global processes and boundary conditions rather than the precise nature of the local resistivity, etc. associated with reconnection (Gonzalez et al. 2016).

\section{Conclusions}

In this review paper we have attempted to summarise the scientific foundations of magnetospheric space weather forecasting. The basic nature of the solar wind magnetosphere interaction is, we argue, well understood. It is driven by magnetic reconnection, and therefore depends on the orientation of the solar wind magnetic field. Whilst the original Dungey picture correctly shows the pattern of magnetospheric circulation, it is important to appreciate that dayside and nightside reconnection do not typically occur in lockstep as simple cartoons such as the one shown in Fig. 1 imply. In fact there is a process of loading and unloading which can be monitored by the size of the polar cap. The unloading process drives strong, structured electrical currents in the ionosphere, and these represent the significant threat to power grids, which is the primary socio-economic impact. Therefore a key goal is to improve the forecasting of substorms. This requires knowledge of both the loading and unloading of energy in the magnetosphere at the magnetopause and in the magnetotail respectively. Recent research has examined the evolution of the solar wind from L1 to the magnetopause, the location, timing, and extent of reconnection on the magnetopause, the physics and temporal variability of reconnection, the nature of bursty bulk flows and their coupling to the inner magnetosphere, and the effects of magnetospheric preconditioning. Observational studies go hand-in-hand with modelling, and improved metrics and benchmarking are aiding the transition to operations. In the future, improved forecasts are likely to derive from three areas: ongoing scientific investigation using existing and future space missions; availability of multipoint operational real time data from hosted payloads and dedicated platforms; and improved modelling schemes. In each of these areas, prospects are bright and we anticipate that there should be a significant improvement in our ability to forecast magnetospheric space weather over the coming years.

Acknowledgements The authors thank the International Space Science Institute for its hospitality in hosting the workshop on the scientific foundations of space weather and for enabling the writing of this article. JPE acknowledges STFC grant ST/N000692/1. LT acknowledges Marie Sklodowska-Curie grant agreement No. 704681. RN is supported by Austrian Science Fund (FWF) I2016-20. The authors thank S.E. Milan, T.D. Phan, E. Gordeev and A. Pulkkinen for their kind assistance with the preparation of Figs. 2, 5, 7 and 8 . The editors and authors thank an anonymous reviewer for very useful comments and suggestions to the original manuscript.

Open Access This article is distributed under the terms of the Creative Commons Attribution 4.0 International License (http://creativecommons.org/licenses/by/4.0/), which permits unrestricted use, distribution, and reproduction in any medium, provided you give appropriate credit to the original author(s) and the source, provide a link to the Creative Commons license, and indicate if changes were made.

\section{References}

S.-I. Akasofu, The development of the auroral substorm. Planet. Space Sci. 12, 273-282 (1964)

B.J. Anderson, K. Takahashi, B.A. Toth, Sensing global Birkeland currents with iridium ${ }^{\circledR}$ engineering magnetometer data. Geophys. Res. Lett. 27(24), 4045-4048 (2000). doi:10.1029/2000GL000094 
B.J. Anderson, K. Takahashi, T. Kamei, C.L. Waters, B.A. Toth, Birkeland current system key parameters derived from Iridium observations: method and initial validation results. J. Geophys. Res. Space Phys. 107(A6), SMP 11-11 (2002). doi:10.1029/2001JA000080

K. Andréeová, T.I. Pulkkinen, T.V. Laitinen, L. Přech, Shock propagation in the magnetosphere: observations and MHD simulations compared. J. Geophys. Res. Space Phys. 113(A9), A09224 (2008). doi:10.1029/ 2008JA013350

V. Angelopoulos, W. Baumjohann, C.F. Kennel, F.V. Coroniti, M.G. Kivelson, R. Pellat, R.J. Walker, H. Lühr, G. Paschmann, Bursty bulk flows in the inner central plasma sheet. J. Geophys. Res. 97(A4), 4027-4039 (1992)

V. Angelopoulos et al., Magnetotail flow bursts: association to global magnetospheric circulation, relationship to ionospheric activity and direct evidence for localization. Geophys. Res. Lett. 24(18), 2271-2274 (1997). doi:10.1029/97GL02355

V. Angelopoulos, F.S. Mozer, R.P. Lin, T. Mukai, K. Tsuruda, R. Lepping, W. Baumjohann, Comment on "Geotail survey of ion flow in the plasma sheet: observations between 10 and 50 RE" by W.R. Paterson et al.. J. Geophys. Res. Space Phys. 104(A8), 17521-17525 (1999). doi:10.1029/1999JA900198

V. Angelopoulos et al., Tail reconnection triggering substorm onset. Science 321, 931-935 (2008)

V. Angelopoulos, A. Runov, X.Z. Zhou, D.L. Turner, S.A. Kiehas, S.S. Li, I. Shinohara, Electromagnetic energy conversion at reconnection fronts. Science 341(6153), 1478-1482 (2013). doi:10.1126/science. 1236992

M. Ashour-Abdalla, M. El-Alaoui, M.L. Goldstein, M. Zhou, D. Schriver, R. Richard, R. Walker, M.G. Kivelson, K.-J. Hwang, Observations and simulations of non-local acceleration of electrons in magnetotail magnetic reconnection events. Nat. Phys. 7(4), 360-365 (2011). http://www.nature.com/nphys/journal/ v7/n4/abs/nphys1903.html\#supplementary-information

U. Auster et al., Space weather magnetometer set with automated AC spacecraft field correction for GeoKompsat-2A, in Proc. '2016 ESA Workshop on Aerospace EMC'. ESA SP, vol. 738 (2016). doi:10.1109/ AeroEMC.2016.7504585

D.N. Baker, T.I. Pulkkinen, V. Angelopoulos, W. Baumjohann, R.L. McPherron, Neutral line model of substorms: past results and present view. J. Geophys. Res. 101, 12975-13010 (1996)

D.N. Baker et al., Timing of magnetic reconnection initiation during a global magnetospheric substorm onset. Geophys. Res. Lett. 29(24), 43 (2002). doi:10.1029/2002GL015539

D.N. Baker et al., A telescopic and microscopic examination of acceleration in the June 2015 geomagnetic storm: magnetospheric multiscale and Van Allen probes study of substorm particle injection. Geophys. Res. Lett. 43(12), 6051-6059 (2016). doi:10.1002/2016GL069643

M.A. Balikhin, A. Runov, S.N. Walker, M. Gedalin, I. Dandouras, Y. Hobara, A. Fazakerley, On the fine structure of dipolarization fronts. J. Geophys. Res. Space Phys. 119(8), 6367-6385 (2014). doi:10.1002/ 2014JA019908

W. Baumjohann, R.A. Treumann, J. LaBelle, R.R. Anderson, Average electric wave spectra across the plasma sheet and their relation to ion bulk speed. J. Geophys. Res. Space Phys. 94(A11), 15221-15230 (1989). doi:10.1029/JA094iA11p15221

W. Baumjohann, Y. Kamide, R. Nakamura, Substorms, storms, and the near-Earth tail. J. Geomagn. Geoelectr. 48, 177 (1996)

J. Birn, R. Nakamura, E.V. Panov, M. Hesse, Bursty bulk flows and dipolarization in MHD simulations of magnetotail reconnection. J. Geophys. Res. Space Phys. 116(12), A01210 (2011). doi:10.1029/ 2010ja016083

J. Birn, M. Hesse, R. Nakamura, S. Zaharia, Particle acceleration in dipolarization events. J. Geophys. Res. 118(5), 1960-1971 (2013). doi:10.1002/jgra.50132

M. Bodeau, Review of better space weather proxies for spacecraft surface charging. IEEE Trans. Plasma Sci. 43(9), 3075-3084 (2015). doi:10.1109/TPS.2015.2441038

L. Bolduc, GIC observations and studies in the Hydro-Quebec power system. J. Atmos. Sol.-Terr. Phys. 64, 1793-1802 (2002)

J.E. Borovsky, M. Hesse, J. Birn, M.M. Kuznetsova, What determines the reconnection rate at the dayside magnetosphere? J. Geophys. Res. Space Phys. 113(A7), A07210 (2008). doi:10.1029/2007JA012645

J.E. Borovsky et al., Estimating the effects of ionospheric plasma on solar wind/ magnetosphere coupling via mass loading of dayside reconnection: ion-plasma-sheet oxygen, plasmaspheric drainage plumes, and the plasma cloak. J. Geophys. Res. 118, 5695-5719 (2013)

G. Branduardi-Raymont et al., AXIOM: advanced X-ray imaging of the magnetosphere. Exp. Astron. 33(23), 403-443 (2012). doi:10.1007/s10686-011-9239-0

J.L. Burch, T.D. Phan, Magnetic reconnection at the dayside magnetopause: advances with MMS. Geophys. Res. Lett. 43(16), 8327-8338 (2016). doi:10.1002/2016GL069787

J.L. Burch, T.E. Moore, R.B. Torbert, B.L. Giles, Magnetospheric multiscale overview and science objectives. Space Sci. Rev. 199(1), 5-21 (2016a). doi:10.1007/s11214-015-0164-9 
J.L. Burch et al., Electron-scale measurements of magnetic reconnection in space. Science 352(6290), aaf2939 (2016b). doi:10.1126/science.aaf2939

P. Cannon et al., Extreme Space Weather: Impacts on Engineered Systems and Infrastructure (Royal Academy of Engineering, London, 2013)

N.A. Case, J.A. Wild, A statistical comparison of solar wind propagation delays derived from multispacecraft techniques. J. Geophys. Res. 117, A02101 (2012). doi:10.1029/2011JA016946

M.D. Cash, S. Witters Hicks, D.A. Biesecker, A.A. Reinard, C.A. de Koning, D.R. Weimer, Validation of an operational product to determine L1 to Earth propagation time delays. Space Weather 14(2), 93-112 (2016). doi:10.1002/2015SW001321

P.A. Cassak, M.A. Shay, Scaling of asymmetric magnetic reconnection: general theory and collisional simulations. Phys. Plasmas 14(10), 102114 (2007). doi:10.1063/1.2795630

L.B.N. Clausen, S.E. Milan, J.B.H. Baker, J.M. Ruohoniemi, K.H. Glassmeier, J.C. Coxon, B.J. Anderson, On the influence of open magnetic flux on substorm intensity: ground- and space-based observations. J. Geophys. Res. Space Phys. 118(6), 2958-2969 (2013). doi:10.1002/jgra.50308

E.W. Cliver, W.F. Dietrich, The 1859 space weather event revisited: limits of extreme activity. J. Space Weather Space Clim. 3(15), A31 (2013). doi:10.1051/swsc/2013053

I.J. Coleman, A multi-spacecraft survey of magnetic field line draping in the dayside magnetosheath. Ann. Geophys. 23(3), 885-900 (2005). doi:10.5194/angeo-23-885-2005

M.R. Collier, J.A. Slavin, R.P. Lepping, A. Szabo, K. Ogilvie, Timing accuracy for the simple planar propagation of magnetic field structures in the solar wind. Geophys. Res. Lett. 25(14), 2509-2512 (1998)

S.W.H. Cowley, M. Lockwood, Excitation and decay of solar wind-driven flows in the magnetosphereionosphere system. Ann. Geophys. 10, 103-115 (1992)

S.W.H. Cowley, C.J. Owen, A simple illustrative model of open flux tube motion over the dayside magnetopause. Planet. Space Sci. 37, 1461-1475 (1989)

L. Dai et al., Near-Earth injection of $\mathrm{MeV}$ electrons associated with intense dipolarization electric fields: Van Allen Probes observations. Geophys. Res. Lett. 42(15), 6170-6179 (2015). doi:10.1002/ 2015GL064955

A.P. Dimmock, K. Nykyri, The statistical mapping of magnetosheath plasma properties based on THEMIS measurements in the magnetosheath interplanetary medium reference frame. J. Geophys. Res. Space Phys. 118(8), 4963-4976 (2013). doi:10.1002/jgra.50465

A.P. Dimmock, K. Nykyri, H. Karimabadi, A. Osmane, T.I. Pulkkinen, A statistical study into the spatial distribution and dawn-dusk asymmetry of dayside magnetosheath ion temperatures as a function of upstream solar wind conditions. J. Geophys. Res. Space Phys. 120(4), 2767-2782 (2015). doi:10.1002/ 2014JA020734

A.P. Dimmock, T.I. Pulkkinen, A. Osmane, K. Nykyri, The dawn-dusk asymmetry of ion density in the dayside magnetosheath and its annual variability measured by THEMIS. Ann. Geophys. 34(5), 511528 (2016). doi:10.5194/angeo-34-511-2016

S. Dubyagin, V. Sergeev, S. Apatenkov, V. Angelopoulos, A. Runov, R. Nakamura, W. Baumjohann, J. McFadden, D. Larson, Can flow bursts penetrate into the inner magnetosphere? Geophys. Res. Lett. 38(8), L08102 (2011). doi:10.1029/2011GL047016

J.W. Dungey, Interplanetary magnetic field and the auroral zones. Phys. Rev. Lett. 6(2), 47-48 (1961)

M.W. Dunlop et al., Extended magnetic reconnection across the dayside magnetopause. Phys. Rev. Lett. 107, 025004 (2011a)

M.W. Dunlop et al., Magnetopause reconnection across wide local time. Ann. Geophys. 29, 1683-1697 (2011b)

J.P. Eastwood, Observing magnetic reconnection: the influence of Jim Dungey, in Magnetospheric Plasma Physics: The Impact of Jim Dungey's Research, ed. by S.W.H. Cowley Frs, D. Southwood, S. Mitton (Springer, Cham, 2015), pp. 181-197. doi:10.1007/978-3-319-18359-6_9

J.P. Eastwood, S.A. Kiehas, Origin and evolution of plasmoids and flux ropes in the magnetotails of Earth and Mars, in Magnetotails in the Solar System (Wiley, New York, 2015), pp. 269-287. doi:10.1002/ 9781118842324.ch16

J.P. Eastwood, T.D. Phan, R.C. Fear, D.G. Sibeck, V. Angelopoulos, M. Oieroset, M.A. Shay, Survival of flux transfer event (FTE) flux ropes far along the tail magnetopause. J. Geophys. Res. Space Phys. 117(9), A08222 (2012). doi:10.1029/2012ja017722

J.P. Eastwood, T.D. Phan, M. Oieroset, M.A. Shay, K. Malakit, M. Swisdak, J.F. Drake, A. Masters, Influence of asymmetries and guide fields on the magnetic reconnection diffusion region in collisionless space plasmas. Plasma Phys. Control. Fusion 55, 124001 (2013)

J.P. Eastwood, M.V. Goldman, H. Hietala, D.L. Newman, R. Mistry, G. Lapenta, Ion reflection and acceleration near magnetotail dipolarization fronts associated with magnetic reconnection. J. Geophys. Res. 120(1), 511-525 (2015a). doi:10.1002/2014JA020516 
J.P. Eastwood, H. Hietala, G. Toth, T.D. Phan, M. Fujimoto, What controls the structure and dynamics of Earth's magnetosphere? Space Sci. Rev. 188(1), 251-286 (2015b). doi:10.1007/s11214-014-0050-x

J.P. Eastwood, D.O. Kataria, C.R. McInnes, N.C. Barnes, P. Mulligan, Sunjammer. Weather 70(1), 27-30 (2015c). doi:10.1002/wea.2438

J.P. Eastwood, E. Biffis, M.A. Hapgood, L. Green, M.M. Bisi, R.D. Bentley, R. Wicks, L.A. McKinnell, M. Gibbs, C. Burnett, The economic impact of space weather: where do we stand? Risk Anal. 37(2), 206-218 (2017). doi:10.1111/risa. 12765

S. Eriksson et al., Magnetospheric multiscale observations of magnetic reconnection associated with KelvinHelmholtz waves. Geophys. Res. Lett. 43(11), 5606-5615 (2016). doi:10.1002/2016GL068783

I.A. Erinmez, J.G. Kappenman, W.A. Radasky, Management of the geomagnetically induced current risks on the national grid company's electric power transmission system. J. Atmos. Sol.-Terr. Phys. 64(5-6), 743-756 (2002). doi:10.1016/s1364-6826(02)00036-6

G. Facskó, I. Honkonen, T. Živković, L. Palin, E. Kallio, K. Ågren, H. Opgenoorth, E.I. Tanskanen, S. Milan, One year in the Earth's magnetosphere: a global MHD simulation and spacecraft measurements. Space Weather 14(5), 351-367 (2016). doi:10.1002/2015SW001355

C.J. Farrugia, N.V. Erkaev, V.K. Jordanova, N. Lugaz, P.E. Sandholt, S. Mühlbachler, R.B. Torbert, Features of the interaction of interplanetary coronal mass ejections/magnetic clouds with the Earth's magnetosphere. J. Atmos. Sol.-Terr. Phys. 99, 14-26 (2013). doi:10.1016/j.jastp.2012.11.014

R.C. Fear, S.E. Milan, A.N. Fazakerley, E.A. Lucek, S.W.H. Cowley, I. Dandouras, The azimuthal extent of three flux transfer events. Ann. Geophys. 26, 2353-2369 (2008)

R.C. Fear, S.E. Milan, K. Oksavik, Determining the axial direction of high-shear flux transfer events: implications for models of FTE structure. J. Geophys. Res. Space Phys. 117(19), A09220 (2012). doi:10.1029/ 2012ja017831

H.S. Fu, Y.V. Khotyaintsev, A. Vaivads, M. André, S. Huang, Electric structure of dipolarization front at sub-proton scale. Geophys. Res. Lett. 39(6), L06105 (2012)

S.A. Fuselier, W.S. Lewis, Properties of near-Earth magnetic reconnection from in-situ observations. Space Sci. Rev. 160, 95-121 (2011)

S.A. Fuselier, H.U. Frey, K.J. Trattner, S.B. Mende, J.L. Burch, Cusp aurora dependence on interplanetary magnetic field $B_{z}$. J. Geophys. Res. 107(A7), 1111 (2002). doi:10.1029/2001JA900165

C. Gabrielse, V. Angelopoulos, A. Runov, D.L. Turner, Statistical characteristics of particle injections throughout the equatorial magnetotail. J. Geophys. Res. Space Phys. 119(4), 2512-2535 (2014). doi:10. 1002/2013JA019638

M.V. Goldman, D.L. Newman, G. Lapenta, What can we learn about magnetotail reconnection from 2D PIC Harris-sheet simulations? Space Sci. Rev. 199(1), 651-688 (2016). doi:10.1007/s11214-015-0154-y

W.D. Gonzalez, J.A. Joselyn, Y. Kamide, H.W. Kroehl, G. Rostoker, B.T. Tsurutani, V.M. Vasyliunas, What is geomagnetic storm? J. Geophys. Res. 99(A4), 5771-5792 (1994)

W.D. Gonzalez et al., Fundamental concepts associated with magnetic reconnection, in Magnetic Reconnection: Concepts and Applications, ed. by W. Gonzalez, E. Parker (Springer, Cham, 2016), pp. 1-32. doi:10.1007/978-3-319-26432-5_1

E. Gordeev, V. Sergeev, I. Honkonen, M. Kuznetsova, L. Rastätter, M. Palmroth, P. Janhunen, G. Tóth, J. Lyon, M. Wiltberger, Assessing the performance of community-available global MHD models using key system parameters and empirical relationships. Space Weather 13(12), 868-884 (2015). doi:10.1002/ 2015SW001307

E. Gordeev, V. Sergeev, N. Tsyganenko, M. Kuznetsova, L. Rastäetter, J. Raeder, G. Tóth, J. Lyon, V. Merkin, M. Wiltberger, The substorm cycle as reproduced by global MHD models. Space Weather 15(1), 131149 (2017). doi:10.1002/2016SW001495

J.T. Gosling, D.J. McComas, J.L. Phillips, S.J. Bame, Geomagnetic activity associated with Earth passage of interplanetary shock disturbances and coronal mass ejections. J. Geophys. Res. 96(5), 7831-7839 (1991)

M.A. Hapgood, Towards a scientific understanding of the risk from extreme space weather. Adv. Space Res. 47(12), 2059-2072 (2011). doi:10.1016/j.asr.2010.02.007

M. Hapgood, Prepare for the coming space weather storm. Nature 484(7394), 311-313 (2012)

H. Hasegawa, Structure and dynamics of the magnetopause and its boundary layers. Monogr. Environ. Earth Planets 1(2), 71-119 (2012)

H. Hasegawa, M. Fujimoto, T.-D. Phan, H. Rème, A. Balogh, M.W. Dunlop, C. Hashimoto, R. TanDokoro, Transport of solar wind into Earth's magnetosphere through rolled-up Kelvin-Helmholtz vortices. Nature 430, 755-758 (2004)

H. Hasegawa et al., Evidence for a flux transfer event generated by multiple X-line reconnection at the magnetopause. Geophys. Res. Lett. 37, L16101 (2010). doi:10.1029/2010GL044219

M. Hesse, T. Neukirch, K. Schindler, M. Kuznetsova, S. Zenitani, The diffusion region in collisionless magnetic reconnection. Space Sci. Rev. 160(1), 3-23 (2011). doi:10.1007/s11214-010-9740-1 
M. Hesse, N. Aunai, D. Sibeck, J. Birn, On the electron diffusion region in planar, asymmetric, systems. Geophys. Res. Lett. 41(24), 8673-8680 (2014). doi:10.1002/2014GL061586

E.W. Hones Jr., Substorm processes in the magnetotail: comments on 'On hot tenuous plasmas, fireballs, and boundary layers in the Earth's magnetotail’ by L.A. Frank, K.L. Ackerson and R.P. Lepping. J. Geophys. Res. 82(35), 5633-5640 (1977)

K.J. Hwang, M.M. Kuznetsova, F. Sahraoui, M.L. Goldstein, E. Lee, G.K. Parks, Kelvin-Helmholtz waves under southward IMF. J. Geophys. Res. 116, A08210 (2011). doi:10.1029/2011JA016596

P. Janhunen, M. Palmroth, T. Laitinen, I. Honkonen, L. Juusola, G. Facsko, T.I. Pulkkinen, The GUMICS4 global MHD magnetosphere-ionosphere coupling simulation. J. Atmos. Sol.-Terr. Phys. 80, 48-59 (2012)

L. Juusola et al., Statistical comparison of seasonal variations in the GUMICS-4 global MHD model ionosphere and measurements. Space Weather 12(10), 582-600 (2014). doi:10.1002/2014SW001082

Y. Kamide, What is an "Intense Geomagnetic Storm"? Space Weather 4, S06008 (2006). doi:10.1029/2006SW000248

K. Kauristie, V.A. Sergeev, O. Amm, M.V. Kubyshkina, J. Jussila, E. Donovan, K. Liou, Bursty bulk flow intrusion to the inner plasma sheet as inferred from auroral observations. J. Geophys. Res. Space Phys. 108(A1), 1040 (2003). doi:10.1029/2002JA009371

Y. Kempf, D. Pokhotelov, O. Gutynska, L.B. Wilson III, B.M. Walsh, S. v. Alfthan, O. Hannuksela, D.G. Sibeck, M. Palmroth, Ion distributions in the Earth's foreshock: hybrid-Vlasov simulation and THEMIS observations. J. Geophys. Res. Space Phys. 120(5), 3684-3701 (2015). doi:10.1002/2014JA020519

L. Kepko, R.L. McPherron, O. Amm, S. Apatenkov, W. Baumjohann, J. Birn, M. Lester, R. Nakamura, T.I. Pulkkinen, V. Sergeev, Substorm current wedge revisited. Space Sci. Rev. 190(1), 1-46 (2015). doi:10. 1007/s11214-014-0124-9

R.L. Kessel, E. Quintana, M. Peredo, Local variations of interplanetary magnetic field at Earth's bow shock. J. Geophys. Res. 104(A11), 24869-24878 (1999)

J. Kissinger, R.L. McPherron, T.S. Hsu, V. Angelopoulos, Diversion of plasma due to high pressure in the inner magnetosphere during steady magnetospheric convection. J. Geophys. Res. Space Phys. 117(A5), A05206 (2012). doi:10.1029/2012JA017579

L.M. Kistler et al., Ion composition and pressure changes in storm time and nonstorm substorms in the vicinity of the near-Earth neutral line. J. Geophys. Res. Space Phys. 111(A11), A11222 (2006). doi:10.1029/ 2006JA011939

S. Knight, Parallel electric fields. Planet. Space Sci. 21(5), 741-750 (1973). doi:10.1016/0032-0633(73) 90093-7

D.J. Knipp, Advances in space weather ensemble forecasting. Space Weather 14(2), 52-53 (2016). doi:10. 1002/2016SW001366

E.A. Kronberg et al., Circulation of heavy ions and their dynamical effects in the magnetosphere: recent observations and models. Space Sci. Rev. 184(1), 173-235 (2014). doi:10.1007/s11214-014-0104-0

M. Kubicka, C. Möstl, T. Amerstorfer, P.D. Boakes, L. Feng, J.P. Eastwood, O. Törmänen, Prediction of geomagnetic storm strength from inner heliospheric in situ observations. Astrophys. J. 833(2), 255 (2016)

M.M. Kuznetsova, M. Hesse, L. Rastätter, A. Taktakishvili, G. Toth, D.L. De Zeeuw, A. Ridley, T.I. Gombosi, Multiscale modeling of magnetospheric reconnection. J. Geophys. Res. Space Phys. 112(A10), A10210 (2007). doi:10.1029/2007JA012316

L.J. Lanzerotti, Comment on "Great magnetic storms" by Tsurutani et al. Geophys. Res. Lett. 19, 1991-1992 (1992). doi:10.1029/92GL02238

B. Lavraud, J.E. Borovsky, Altered solar wind-magnetosphere interaction at low Mach numbers: coronal mass ejections. J. Geophys. Res. Space Phys. 113(A9), A00B08 (2008). doi:10.1029/2008JA013192

B. Lavraud, J.E. Borovsky, A.J. Ridley, E.W. Pogue, M.F. Thomsen, H. Rème, A.N. Fazakerley, E.A. Lucek, Strong bulk plasma acceleration in Earth's magnetosheath: a magnetic slingshot effect? Geophys. Res. Lett. 34(14), L14102 (2007). doi:10.1029/2007GL030024

B. Lavraud, C. Foullon, C.J. Farrugia, J.P. Eastwood, The magnetopause, its boundary layers and pathways to the magnetotail, in The Dynamic Magnetosphere, ed. by W. Liu, M. Fujimoto (Springer, Berlin, 2011)

L.C. Lee, Z.F. Fu, A theory of magnetic flux transfer at the Earth's magnetopause. Geophys. Res. Lett. 12, 105-108 (1985)

R.P. Lepping, C.-C. Wu, K. McClernan, Two-dimensional curvature of large angle interplanetary MHD discontinuity surfaces: IMP-8 and WIND observations. J. Geophys. Res. 108(A7), 1279 (2003). doi:10. 1029/2002JA009640

X.L. Li, I. Roth, M. Temerin, J.R. Wygant, M.K. Hudson, J.B. Blake, Simulation of the prompt energization and transport of radiation belt particles during the March 24, 1991 SSC. Geophys. Res. Lett. 20(22), 2423-2426 (1993). doi:10.1029/93g102701

J. Liu, V. Angelopoulos, A. Runov, X.Z. Zhou, On the current sheets surrounding dipolarizing flux bundles in the magnetotail: the case for wedgelets. J. Geophys. Res. Space Phys. 118, 2000-2010 (2013). doi:10.1002/jgra.50092 
J. Liu, V. Angelopoulos, X.Z. Zhou, A. Runov, Magnetic flux transport by dipolarizing flux bundles. J. Geophys. Res. Space Phys. 119, 909-926 (2014). doi:10.1002/2013JA019395

J. Liu, V. Angelopoulos, X.-J. Zhang, D.L. Turner, C. Gabrielse, A. Runov, J. Li, H.O. Funsten, H.E. Spence, Diolarizing flux bundles in the cisgeosynchronous magnetosphere: relationship between electric fields and energetic particle injections. J. Geophys. Res. Space Phys. 121, 1362-1376 (2016). doi:10.1002/ 2015JA021691

M. Longmore, S.J. Schwartz, J. Geach, B.M.A. Cooling, I. Dandouras, E.A. Lucek, A.N. Fazakerley, Dawndusk asymmetries and sub-Alfvénic flow in the high and low latitude magnetosheath. Ann. Geophys. 23(10), 3351-3364 (2005). doi:10.5194/angeo-23-3351-2005

M. Longmore, S.J. Schwartz, E.A. Lucek, Rotation of the magnetic field in Earth's magnetosheath by bulk magnetosheath plasma flow. Ann. Geophys. 24(1), 339-354 (2006). doi:10.5194/angeo-24-339-2006

R.E. Lopez, M. Wiltberger, S. Hernandez, J.G. Lyon, Solar wind density control of energy transfer to the magnetosphere. Geophys. Res. Lett. 31(8), L08804 (2004). doi:10.1029/2003GL018780

R.E. Lopez, S. Hernandez, M. Wiltberger, C.L. Huang, E.L. Kepko, H. Spence, C.C. Goodrich, J.G. Lyon, Predicting magnetopause crossings at geosynchronous orbit during the Halloween storms. Space Weather 5(1), S01005 (2007). doi:10.1029/2006SW000222

R.E. Lopez, V.G. Merkin, J.G. Lyon, The role of the bow shock in solar wind-magnetosphere coupling. Ann. Geophys. 29(6), 1129-1135 (2011). doi:10.5194/angeo-29-1129-2011

T.M. Loto'aniu, H.J. Singer, J.V. Rodriguez, J. Green, W. Denig, D. Biesecker, V. Angelopoulos, Space weather conditions during the Galaxy 15 spacecraft anomaly. Space Weather 13(8), 484-502 (2015). doi:10.1002/2015sw001239

J.J. Love, Credible occurrence probabilities for extreme geophysical events: earthquakes, volcanic eruptions, magnetic storms. Geophys. Res. Lett. 39(6), L10301 (2012). doi:10.1029/2012g1051431

J.G. Lyon, J.A. Fedder, C.M. Mobarry, The Lyon-Fedder-Mobarry (LFM) global MHD magnetospheric simulation code. J. Atmos. Sol.-Terr. Phys. 66(15-16), 1333-1350 (2004). doi:10.1016/j.jastp.2004.03.020

P. MacNeice, M. Hesse, M. Kuznetsova, M. Maddox, L. Rastaetter, D. Berrios, A. Pulkkinen, Transforming community access to space science models. Eos 93(15), 153-154 (2012). doi:10.1029/2012EO150002

R.L. McPherron, Growth phase of magnetospheric substorms. J. Geophys. Res. 75(28), 5592-5599 (1970). doi:10.1029/JA075i028p05592

V.G. Merkin, J.G. Lyon, Effects of the low-latitude ionospheric boundary condition on the global magnetosphere. J. Geophys. Res. Space Phys. 115(A10), A10202 (2010). doi:10.1029/2010JA015461

S.E. Milan, Both solar wind-magnetosphere coupling and ring current intensity control the size of the auroral oval. Geophys. Res. Lett. 36, L18101 (2009). doi:10.1029/2009GL039997

S.E. Milan, Sun et lumiere: solar wind-magnetosphere coupling as deduced from ionospheric flows and polar auroras, in Magnetospheric Plasma Physics: The Impact of Jim Dungey's Research, ed. by S.W.H. Cowley Frs, D. Southwood, S. Mitton (Springer, Cham, 2015), pp. 33-64. doi:10.1007/978-3-319-18359$6 \_2$

S.E. Milan, L.B.N. Clausen, J.C. Coxon, J.A. Carter, M.-T. Walach, K. Laundal, N. Østgaard, P. Tenfjord, J. Reistad, K. Snekvik, H. Korth, B.J. Anderson, Overview of solar wind-magnetosphere-ionosphereatmosphere coupling and the generation of magnetospheric currents. Space Sci. Rev. 206(1-4), 547-573 (2017). doi:10.1007/s11214-017-0333-0

Y. Miyashita et al., Geotail observations of signatures in the near-Earth magnetotail for the extremely intense substorms of the 30 October 2003 storm. J. Geophys. Res. Space Phys. 110(A9), A09S25 (2005). doi: $10.1029 / 2005$ JA011070

T. Nagai, M. Fujimoto, R. Nakamura, W. Baumjohann, A. Ieda, I. Shinohara, S. Machida, Y. Saito, T. Mukai, Solar wind control of the radial distance of the magnetic reconnection site in the magnetotail. J. Geophys. Res. Space Phys. 110(A9), A09208 (2005). doi:10.1029/2005JA011207

R. Nakamura, W. Baumjohann, R. Schödel, M. Brittnacher, V.A. Sergeev, M. Kubyshkina, T. Mukai, K. Liou, Earthward flow bursts, auroral streamers, and small expansions. J. Geophys. Res. Space Phys. 106(A6), 10791-10802 (2001). doi:10.1029/2000JA000306

R. Nakamura et al., Motion of the dipolarization front during a flow burst event observed by Cluster. Geophys. Res. Lett. 29(20), 1942 (2002). doi:10.1029/2002GL015763

R. Nakamura et al., Spatial scale of high-speed flows in the plasma sheet observed by Cluster. Geophys. Res. Lett. 31(9), L09804 (2004). doi:10.1029/2004g1019558

R. Nakamura, A. Retinò, W. Baumjohann, M. Volwerk, N. Erkaev, B. Klecker, E.A. Lucek, I. Dandouras, M. André, Y. Khotyaintsev, Evolution of dipolarization in the near-Earth current sheet induced by Earthward rapid flux transport. Ann. Geophys. 27(4), 1743-1754 (2009). doi:10.5194/angeo-27-1743-2009

R. Nakamura et al., Flow bouncing and electron injection observed by Cluster. J. Geophys. Res. Space Phys. 118(5), 2055-2072 (2013). doi:10.1002/jgra.50134

National Research Council, Severe Space Weather Events-Understanding Societal and Economic Impacts: A Workshop Report (The National Academies Press, Washington DC, 2008) 
K. Nykyri, Impact of MHD shock physics on magnetosheath asymmetry and Kelvin-Helmholtz instability. J. Geophys. Res. Space Phys. 118(8), 5068-5081 (2013). doi:10.1002/jgra.50499

M. Oieroset, D. Sundkvist, C.C. Chaston, T.D. Phan, F.S. Mozer, J.P. McFadden, V. Angelopoulos, L. Andersson, J.P. Eastwood, Observations of plasma waves in the colliding jet region of a magnetic flux rope flanked by two active X lines at the subsolar magnetopause. J. Geophys. Res. Space Phys. 119(8), 6256-6272 (2014). doi:10.1002/2014ja020124

D.M. Oliveira, J. Raeder, Impact angle control of interplanetary shock geoeffectiveness. J. Geophys. Res. Space Phys. 119(10), 8188-8201 (2014). doi:10.1002/2014JA020275

N. Omidi, D.G. Sibeck, Flux transfer events in the cusp. Geophys. Res. Lett. 34, L04106 (2007). doi:10.1029/ 2006GL028698

M. Palmroth, T.I. Pulkkinen, P. Janhunen, C.C. Wu, Stormtime energy transfer in global MHD simulation. J. Geophys. Res. Space Phys. 108(A1), 1048 (2003). doi:10.1029/2002ja009446

M. Palmroth, T.V. Laitinen, T.I. Pulkkinen, Magnetopause energy and mass transfer: results from a global MHD simulation. Ann. Geophys. 24, 3467-3480 (2006)

E.V. Panov et al., Multiple overshoot and rebound of a bursty bulk flow. Geophys. Res. Lett. 37(8), L08103 (2010). doi:10.1029/2009GL041971

E.V. Panov, W. Baumjohann, R. Nakamura, O. Amm, M.V. Kubyshkina, K.H. Glassmeier, J.M. Weygand, V. Angelopoulos, A.A. Petrukovich, V.A. Sergeev, Ionospheric response to oscillatory flow braking in the magnetotail. J. Geophys. Res. Space Phys. 118(4), 1529-1544 (2013a). doi:10.1002/jgra.50190

E.V. Panov, M.V. Kubyshkina, R. Nakamura, W. Baumjohann, V. Angelopoulos, V.A. Sergeev, A.A. Petrukovich, Oscillatory flow braking in the magnetotail: THEMIS statistics. Geophys. Res. Lett. 40(11), 2505-2510 (2013b). doi:10.1002/grl.50407

G. Paschmann, B.U.Ö. Sonnerup, I. Papamastorakis, N. Sckopke, G. Haerendel, S.J. Bame, J.R. Asbridge, J.T. Gosling, C.T. Russell, R.C. Elphic, Plasma acceleration at the Earth's magnetopause: evidence for reconnection. Nature 282, 243-246 (1979)

G. Paschmann, I. Papamastorakis, W. Baumjohann, N. Sckopke, C.W. Carlson, B.U.Ö. Sonnerup, H. Lühr, The magnetopause for large magnetic shear: AMPTE/IRM observations. J. Geophys. Res. Space Phys. 91(A10), 11099-11115 (1986). doi:10.1029/JA091iA10p11099

G. Paschmann, M. Øieroset, T. Phan, In-situ observations of reconnection in space. Space Sci. Rev. 178, 385 (2013). doi:10.1007/s11214-012-9957-2

K.I. Paularena, J.D. Richardson, M.A. Kolpak, C.R. Jackson, G.L. Siscoe, A dawn-dusk density asymmetry in Earth's magnetosheath. J. Geophys. Res. Space Phys. 106(A11), 25377-25394 (2001). doi:10.1029/ 2000JA000177

A. Petrukovich, A. Artemyev, R. Nakamura, Magnetotail reconnection, in Magnetic Reconnection: Concepts and Applications, ed. by W. Gonzalez, E. Parker (Springer, Cham, 2016), pp. 277-313. doi:10.1007/9783-319-26432-5_7

Y. Pfau-Kempf, H. Hietala, S.E. Milan, L. Juusola, S. Hoilijoki, U. Ganse, S. von Alfthan, M. Palmroth, Evidence for transient, local ion foreshocks caused by dayside magnetopause reconnection. Ann. Geophys. 34(11), 943-959 (2016). doi:10.5194/angeo-34-943-2016

T.D. Phan et al., Extended magnetic reconnection at the Earth's magnetopause from detection of bi-directional jets. Nature 404, 848-850 (2000)

T.D. Phan, J.T. Gosling, G. Paschmann, C. Pasma, J.F. Drake, M. Oieroset, D. Larson, R.P. Lin, M.S. Davis, The dependence of magnetic reconnection on plasma beta and magnetic shear: evidence from solar wind observations. Astrophys. J. Lett. 719(2), L199-L203 (2010). doi:10.1088/2041-8205/719/2/1199

T.D. Phan, G. Paschmann, J.T. Gosling, M. Oieroset, M. Fujimoto, J.F. Drake, V. Angelopoulos, The dependence of magnetic reconnection on plasma beta and magnetic shear: evidence from magnetopause observations. Geophys. Res. Lett. 40(1), 11-16 (2013). doi:10.1029/2012g1054528

C. Pollock et al., Fast plasma investigation for magnetospheric multiscale. Space Sci. Rev. 199(1), 331-406 (2016). doi:10.1007/s11214-016-0245-4

D.H. Pontius Jr., R.A. Wolf, Transient flux tubes in the terrestrial magnetosphere. Geophys. Res. Lett. 17(1), 49-52 (1990)

K.G. Powell, P.L. Roe, T.J. Linde, T.I. Gombosi, D.L. De Zeeuw, A solution-adaptive upwind scheme for ideal magnetohydrodynamics. J. Comput. Phys. 154(2), 284-309 (1999). doi:10.1006/jcph.1999.6299

Z.Y. Pu, J. Raeder, J. Zhong, Y.V. Bogdanova, M. Dunlop, C.J. Xiao, X.G. Wang, A. Fazakerley, Magnetic topologies of an in vivo FTE observed by Double Star/TC-1 at Earth's magnetopause. Geophys. Res. Lett. 40(14), 3502-3506 (2013). doi:10.1002/grl.50714

T.I. Pulkkinen, M. Palmroth, R.L. McPherron, What drives magnetospheric activity under northward IMF conditions? Geophys. Res. Lett. 34(18), L18104 (2007). doi:10.1029/2007GL030619

A. Pulkkinen, M. Hesse, S. Habib, L. Van der Zel, B. Damsky, F. Policelli, D. Fugate, W. Jacobs, E. Creamer, Solar shield: forecasting and mitigating space weather effects on high-voltage power transmission systems. Nat. Hazards 53(2), 333-345 (2010). doi:10.1007/s11069-009-9432-x 
A. Pulkkinen et al., Geospace environment modeling 2008-2009 challenge: ground magnetic field perturbations. Space Weather 9(2), S02004 (2011). doi:10.1029/2010SW000600

A. Pulkkinen et al., Community-wide validation of geospace model ground magnetic field perturbation predictions to support model transition to operations. Space Weather 11(6), 369-385 (2013). doi:10.1002/ swe. 20056

A. Pulkkinen, E. Bernabeu, J. Eichner, A. Viljanen, C. Ngwira, Earth Planets Space 67, 93 (2015). doi:10.1186/s40623-015-0255-6

T.I. Pulkkinen, A.P. Dimmock, A. Lakka, A. Osmane, E. Kilpua, M. Myllys, E.I. Tanskanen, A. Viljanen, Magnetosheath control of solar wind-magnetosphere coupling efficiency. J. Geophys. Res. Space Phys. 121(9), 8728-8739 (2016). doi:10.1002/2016JA023011

T. Pytte, R.L. McPherron, E.W. Hones, H.I. West, Multiple-satellite studies of magnetospheric substorms: distinction between polar magnetic substorms and convection-driven negative bays. J. Geophys. Res. Space Phys. 83(A2), 663-679 (1978). doi:10.1029/JA083iA02p00663

J.M. Quinn, D.J. Southwood, Observations of parallel ion energization in the equatorial region. J. Geophys. Res. Space Phys. 87(A12), 10536-10540 (1982). doi:10.1029/JA087iA12p10536

J. Raeder, Flux transfer events: 1. Generation mechanism for strong southward IMF. Ann. Geophys. 24, 381392 (2006)

J. Raeder, Y.L. Wang, T.J. Fuller-Rowell, H.J. Singer, Global simulation of magnetospheric space weather effects of the Bastille Day storm. Sol. Phys. 204(1), 323-337 (2001). doi:10.1023/a:1014228230714

J. Raeder, D. Larson, W. Li, E.L. Kepko, T. Fuller-Rowell, OpenGGCM simulations for the THEMIS Mission. Space Sci. Rev. 141(1), 535-555 (2008). doi:10.1007/s11214-008-9421-5

A. Retinò et al., Cluster multispacecraft observations at the high-latitude duskside magnetopause: implications for continuous and component magnetic reconnection. Ann. Geophys. 23(2), 461-473 (2005). doi:10.5194/angeo-23-461-2005

I.G. Richardson, E.W. Cliver, H.V. Cane, Sources of geomagnetic storms for solar minimum and maximum conditions during 1972-2000. Geophys. Res. Lett. 28(13), 2569-2572 (2001)

I.G. Richardson et al., Major geomagnetic storms (Dst $\leq-100 \mathrm{nT})$ generated by corotating interaction regions. J. Geophys. Res. 111, A07S09 (2006). doi:10.1029/2005JA011476

A.J. Ridley, T.I. Gombosi, D.L. DeZeeuw, Ionospheric control of the magnetosphere: conductance. Ann. Geophys. 22(2), 567-584 (2004). doi:10.5194/angeo-22-567-2004

P. Riley, On the probability of occurrence of extreme space weather events. Space Weather 10(12), S02012 (2012). doi:10.1029/2011sw000734

R.G. Roble, E.C. Ridley, A thermosphere-ionosphere-mesosphere-electrodynamics general circulation model (time-GCM): equinox solar cycle minimum simulations (30-500 km). Geophys. Res. Lett. 21(6), 417420 (1994). doi:10.1029/93GL03391

G. Rostoker, S.-I. Akasofu, J. Foster, R.A. Greenwald, Y. Kamide, A.T.Y. Lui, R.L. McPherron, C.T. Russell, Magnetospheric substorms—definition and signatures. J. Geophys. Res. 85(A4), 1663-1668 (1980)

A. Runov, V. Angelopoulos, X.Z. Zhou, X.J. Zhang, S. Li, F. Plaschke, J. Bonnell, A THEMIS multicase study of dipolarization fronts in the magnetotail plasma sheet. J. Geophys. Res. Space Phys. 116(15), A05216 (2011). doi:10.1029/2010ja016316

C.T. Russell, R.C. Elphic, Initial ISEE magnetometer results: magnetopause observations. Space Sci. Rev. 22, 681-715 (1978)

J. Šafránková, M. Hayosh, O. Gutynska, Z. Němeček, L. Přech, Reliability of prediction of the magnetosheath BZ component from interplanetary magnetic field observations. J. Geophys. Res. Space Phys. 114(A12), A12213 (2009). doi:10.1029/2009JA014552

A. Sandroos, I. Honkonen, S. von Alfthan, M. Palmroth, Multi-GPU simulations of Vlasov's equation using Vlasiator. Parallel Comput. 39(8), 306-318 (2013). doi:10.1016/j.parco.2013.05.001

D. Schmid, M. Volwerk, R. Nakamura, W. Baumjohann, M. Heyn, A statistical and event study of magnetotail dipolarization fronts. Ann. Geophys. 29(9), 1537-1547 (2011). doi:10.5194/angeo-29-1537-2011

D. Schmid et al., A comparative study of dipolarization fronts at MMS and Cluster. Geophys. Res. Lett. 43(12), 6012-6019 (2016). doi:10.1002/2016GL069520

R. Schödel, W. Baumjohann, R. Nakamura, V.A. Sergeev, T. Mukai, Rapid flux transport in the central plasma sheet. J. Geophys. Res. Space Phys. 106(A1), 301-313 (2001). doi:10.1029/2000JA900139

M. Scholer, Magnetic flux transfer at the magnetopause based on single X-line bursty reconnection. Geophys. Res. Lett. 15, 291-294 (1988)

C.J. Schrijver et al., Understanding space weather to shield society: a global road map for 2015-2025 commissioned by COSPAR and ILWS. Adv. Space Res. 55(12), 2745-2807 (2015). doi:10.1016/j.asr.2015. 03.023

S.J. Schwartz et al., Cross-scale: multi-scale coupling in space plasmas. Exp. Astron. 23, 1001-1015 (2009)

V.A. Sergeev, V. Angelopoulos, J.T. Gosling, C.A. Cattell, C.T. Russell, Detection of localized, plasma depleted flux tubes or bubbles in the midtail plasma sheet. J. Geophys. Res. 101(A5), 10817-10826 (1996) 
V.A. Sergeev, N.A. Tsyganenko, V. Angelopoulos, Dynamical response of the magnetotail to changes of the solar wind direction: an MHD modeling perspective. Ann. Geophys. 26(8), 2395-2402 (2008). doi:10. 5194/angeo-26-2395-2008

V.A. Sergeev, V. Angelopoulos, R. Nakamura, Recent advances in understanding substorm dynamics. Geophys. Res. Lett. 39, L05101 (2012). doi:10.1029/2012g1050859

V.A. Sergeev, D.A. Sormakov, V. Angelopoulos, A missing variable in solar wind-magnetosphere-ionosphere coupling studies. Geophys. Res. Lett. 41(23), 8215-8220 (2014). doi:10.1002/2014GL062271

J.H. Shue et al., Magnetopause location under extreme solar wind conditions. J. Geophys. Res. Space Phys. 103(A8), 17691-17700 (1998). doi:10.1029/98JA01103

M.I. Sitnov, V.G. Merkin, J. Raeder, Great mysteries of the Earth's magnetotail. EOS Trans. AGU 97 (2016). doi:10.1029/2016EO048185

J.A. Slavin, E.J. Smith, B.T. Tsurutani, D.G. Sibeck, H.J. Singer, D.N. Baker, J.T. Gosling, E.W. Hones, F.L. Scarf, Substorm associated traveling compression regions in the distant tail: Isee-3 Geotail observations. Geophys. Res. Lett. 11(7), 657-660 (1984). doi:10.1029/GL011i007p00657

P. Song, C.T. Russell, Model of the formation of the low-latitude boundary layer for strongly northward interplanetary magnetic field. J. Geophys. Res. 97(A2), 1411-1420 (1992)

D.J. Southwood, C.J. Farrugia, M.A. Saunders, What are flux transfer events? Planet. Space Sci. 36, 503-508 (1988)

H.E. Spence et al., The Magnetospheric Constellation Mission Dynamic Response and Coupling Observatory (DRACO) understanding the global dynamics of the structured magnetotail, Greenbelt, MD (2001)

H.E. Spence et al., The Magnetospheric Constellation (MC) global dynamics of the structured magnetotail, Washington, DC (2004)

J.E. Stawarz et al., Observations of turbulence in a Kelvin-Helmholtz event on 8 September 2015 by the Magnetospheric Multiscale mission. J. Geophys. Res. Space Phys. 121(11), 11021 (2016). doi:10.1002/ 2016JA023458

E.C. Stone, A.M. Frandsen, R.A. Mewaldt, E.R. Christian, D. Margolies, J.F. Ormes, F. Snow, The advanced composition explorer. Space Sci. Rev. 86, 1-22 (1998)

M. Swisdak, B.N. Rogers, J.F. Drake, M.A. Shay, Diamagnetic suppression of component magnetic reconnection at the magnetopause. J. Geophys. Res. Space Phys. 108(A5), 1218 (2003). doi:10.1029/ $2002 \mathrm{ja009726}$

M. Swisdak, M. Opher, J.F. Drake, F.A. Bibi, The vector direction of the interstellar magnetic field outside the heliosphere. Astrophys. J. 710(2), 1769-1775 (2010). doi:10.1088/0004-637x/710/2/1769

K.G. Tanaka, M. Fujimoto, I. Shinohara, Physics of magnetopause reconnection: a study of the combined effects of density asymmetry, velocity shear, and guide field. Int. J. Geophys. 2010, 202583 (2010). doi:10. $1155 / 2010 / 202583$

T. Terasawa et al., Solar wind control of density and temperature in the near-Earth plasma sheet: WIND/GEOTAIL collaboration. Geophys. Res. Lett. 24(8), 935-938 (1997)

F. Toffoletto, S. Sazykin, R. Spiro, R. Wolf, Inner magnetospheric modeling with the rice convection model. Space Sci. Rev. 107(1-2), 175-196 (2003). doi:10.1023/a:1025532008047

G. Toth et al., Space Weather Modeling Framework: a new tool for the space science community. J. Geophys. Res. Space Phys. 110(A12), A12226 (2005). doi:10.1029/2005ja011126

G. Toth et al., Adaptive numerical algorithms in space weather modeling. J. Comput. Phys. 231(3), 870-903 (2012). doi:10.1016/j.jcp.2011.02.006

G. Tóth et al., Extended magnetohydrodynamics with embedded particle-in-cell simulation of Ganymede's magnetosphere. J. Geophys. Res. Space Phys. 121(2), 1273-1293 (2016). doi:10.1002/2015JA021997

K.J. Trattner, J.S. Mulcock, S.M. Petrinec, S.A. Fuselier, Location of the reconnection line at the magnetopause during southward IMF conditions. Geophys. Res. Lett. 34(3), L03108 (2007a). doi:10.1029/ $2006 \mathrm{gl028397}$

K.J. Trattner, J.S. Mulcock, S.M. Petrinec, S.A. Fuselier, Probing the boundary between antiparallel and component reconnection during southward interplanetary magnetic field conditions. J. Geophys. Res. Space Phys. 112(A8), A08210 (2007b). doi:10.1029/2007ja012270

K.J. Trattner, S.M. Petrinec, S.A. Fuselier, T.D. Phan, The location of reconnection at the magnetopause: testing the maximum magnetic shear model with THEMIS observations. J. Geophys. Res. Space Phys. 117, A01201 (2012). doi:10.1029/2011ja016959

L. Trenchi, M.F. Marcucci, G. Pallocchia, G. Consolini, M.B. Bavassano Cattaneo, A.M. Di Lellis, H. Rème, L. Kistler, C.M. Carr, J.B. Cao, Occurrence of reconnection jets at the dayside magnetopause: Double Star observations. J. Geophys. Res. Space Phys. 113(A7), A07S10 (2008). doi:10.1029/2007JA012774

B.T. Tsurutani, F.L. Guarnieri, G.S. Lakhina, T. Hada, Rapid evolution of magnetic decreases (MDs) and discontinuities in the solar wind: ACE and Cluster. Geophys. Res. Lett. 32, L10103 (2005). doi:10.1029/ 2004GL022151 
L. Turc, D. Fontaine, P. Savoini, E.K.J. Kilpua, Magnetic clouds' structure in the magnetosheath as observed by Cluster and Geotail: four case studies. Ann. Geophys. 32(10), 1247-1261 (2014a). doi:10.5194/ angeo-32-1247-2014

L. Turc, D. Fontaine, P. Savoini, E.K.J. Kilpua, A model of the magnetosheath magnetic field during magnetic clouds. Ann. Geophys. 32(2), 157-173 (2014b). doi:10.5194/angeo-32-157-2014

L. Turc, C.P. Escoubet, D. Fontaine, E.K.J. Kilpua, S. Enestam, Cone angle control of the interaction of magnetic clouds with the Earth's bow shock. Geophys. Res. Lett. 43(10), 4781-4789 (2016). doi:10.1002/ 2016GL068818

L. Turc, D. Fontaine, C.P. Escoubet, E.K.J. Kilpua, A.P. Dimmock, Statistical study of the alteration of the magnetic structure of magnetic clouds in the Earth's magnetosheath. J. Geophys. Res. Space Phys. 122, 2956-2972 (2017). doi:10.1002/2016JA023654

V.M. Vasyliunas, Theoretical models of magnetic field line merging. Rev. Geophys. 13(1), 303-336 (1975)

V.M. Vasyliunas, Relation between magnetic fields and electric currents in plasmas. Ann. Geophys. 23(2589), 2597 (2005)

V.M. Vasyliūnas, The largest imaginable magnetic storm. J. Atmos. Sol.-Terr. Phys. 73(11-12), 1444-1446 (2011). doi:10.1016/j.jastp.2010.05.012

S. von Alfthan, D. Pokhotelov, Y. Kempf, S. Hoilijoki, I. Honkonen, A. Sandroos, M. Palmroth, Vlasiator: first global hybrid-Vlasov simulations of Earth's foreshock and magnetosheath. J. Atmos. Sol.-Terr. Phys. 120, 24-35 (2014). doi:10.1016/j.jastp.2014.08.012

R. Walker et al., Source and loss processes in the magnetotail. Space Sci. Rev. 88(1-2), 285-353 (1999). doi:10.1023/a:1005207918263

B.M. Walsh, D.G. Sibeck, Y. Wang, D.H. Fairfield, Dawn-dusk asymmetries in the Earth's magnetosheath. J. Geophys. Res. Space Phys. 117(A12), A12211 (2012). doi:10.1029/2012JA018240

B.M. Walsh, J.C. Foster, P.J. Erickson, D.G. Sibeck, Simultaneous ground- and space-based observations of the plasmaspheric plume and reconnection. Science 343(6175), 1122-1125 (2014). doi:10.1126/science. 1247212

W. Wang, M. Wiltberger, A.G. Burns, S.C. Solomon, T.L. Killeen, N. Maruyama, J.G. Lyon, Initial results from the coupled magnetosphere-ionosphere-thermosphere model: thermosphere-ionosphere responses. J. Atmos. Sol.-Terr. Phys. 66(15-16), 1425-1441 (2004). doi:10.1016/j.jastp.2004.04.008

D.R. Weimer, J.H. King, Improved calculations of interplanetary magnetic field phase front angles and propagation time delays. J. Geophys. Res. 113, A01105 (2008). doi:10.1029/2007JA012452

M. Wiltberger, W. Wang, A.G. Burns, S.C. Solomon, J.G. Lyon, C.C. Goodrich, Initial results from the coupled magnetosphere ionosphere thermosphere model: magnetospheric and ionospheric responses. J. Atmos. Sol.-Terr. Phys. 66(15-16), 1411-1423 (2004). doi:10.1016/j.jastp.2004.03.026

R.A. Wolf, M. Harel, R.W. Spiro, G.H. Voigt, P.H. Reiff, C.K. Chen, Computer-simulation of inner magnetospheric dynamics for the magnetic storm of July 29, 1977. J. Geophys. Res. Space Phys. 87(A8), 5949-5962 (1982). doi:10.1029/JA087iA08p05949

Y. Yu, A.J. Ridley, Response of the magnetosphere-ionosphere system to a sudden southward turning of interplanetary magnetic field. J. Geophys. Res. Space Phys. 114(A3), A03216 (2009). doi:10.1029/ 2008JA013292

X.Z. Zhou, V. Angelopoulos, J. Liu, A. Runov, S.S. Li, On the origin of pressure and magnetic perturbations ahead of dipolarization fronts. J. Geophys. Res. Space Phys. 119(1), 211-220 (2014). doi:10.1002/ $2013 \mathrm{ja0} 019394$ 